Article

\title{
Agricultural Support Policies and China's Cyclical Evolutionary Path of Agricultural Economic Growth
}

\author{
Xiangdong Guo ${ }^{1, * \mathbb{C}}$, Pei Lung ${ }^{2}$, Jianli Sui ${ }^{3}$, Ruiping Zhang ${ }^{1}$ and Chao Wang ${ }^{1}$ \\ 1 School of Economics and Management, Beijing Jiaotong University, Beijing 100044, China; \\ rpzhang@bjtu.edu.cn (R.Z.); chaowang@bjtu.edu.cn (C.W.) \\ 2 The Daniels College of Business, University of Denver, Denver, CO 80208, USA; Pei.lung@du.edu \\ 3 Center for Quantitative Economics, Jilin University, Changchun 130012, China; jlsui@163.com \\ * Correspondence: xiangdong.guo@bjtu.edu.cn; Tel.: +86-10-5168-8044
}

check for updates

Citation: Guo, X.; Lung, P.; Sui, J.;

Zhang, R.; Wang, C. Agricultural

Support Policies and China's Cyclical Evolutionary Path of Agricultural Economic Growth. Sustainability 2021, 13, 6134. https://doi.org/10.3390/ su13116134

Academic Editor: Aaron K. Hoshide

Received: 14 April 2021

Accepted: 27 May 2021

Published: 29 May 2021

Publisher's Note: MDPI stays neutral with regard to jurisdictional claims in published maps and institutional affiliations.

Copyright: (C) 2021 by the authors Licensee MDPI, Basel, Switzerland. This article is an open access article distributed under the terms and conditions of the Creative Commons Attribution (CC BY) license (https:// creativecommons.org/licenses/by/ $4.0 /)$.

\begin{abstract}
Due to the weak nature of agricultural production, governments usually adopt supportive policies to protect food security. To discern the growth of agriculture from 2001 to 2018 under China's agricultural support policies, we use the nonlinear MS(M)-AR(p) model to distinguish China's agricultural economic cycle into three growth regimes-rapid, medium, and low-and analyze the probability of shifts and maintenance among the different regimes. We further calculated the average duration of each regime. Moreover, we calculated the growth regime transfers for specific times. In this study, we find that China's agricultural economy has maintained a relatively consistent growth trend with the support of China's proactive agricultural policies. However, China's agricultural economy tends to maintain a low-growth status in the long-term. Finally, we make policy recommendations for agricultural development based on our findings that continue existing agricultural policies and strengthen support for agriculture, forestry, and animal husbandry.
\end{abstract}

Keywords: agricultural development; agricultural economic cycle; agricultural policies

\section{Introduction}

Agriculture not only affects the macroeconomics of a country but is also associated with the food security and employment issues of a country, particularly for developing countries. With the majority of countries in the world still in the developing stage and a very high proportion of the population still underdeveloped, development remains a central topic in the world economy. As early as 1946, economists Burns and Mitchell emphasized that economic growth can be effectively guided only by a thorough analysis of the mechanisms of change inherent in economic growth [1].

The agricultural surplus theory considers a highly developed agricultural economy as the fundamental condition for macroeconomic development. For this reason, the Chinese government introduced beneficial agricultural policies every year since 2004 to support agricultural development. China's economy has been increasing with a double digit high growth rate in the past few decades. The growth rate has only slowed down slightly in recent years, but it is still one of the fastest growing economies in the world. Within this historical context, what are the dynamics that drive China's agricultural economic growth? In this paper, we investigate the true underlying dynamics of China's agricultural economy during this period of time, and summarize its experience to incentivize further growth of China's agricultural economy.

The available literature focuses mainly on the factors influencing the growth of agriculture. Even though agriculture may grow rapidly in the short term, long-term growth is constrained by factors such as overconsumption of natural resources and environmental pollution [2]. The role of water use in driving agricultural growth in different regions of China was based on a panel vector autoregressive model [3]. Infrastructure development has a catalytic effect on China's agricultural GDP [4]. Agricultural production and 
development can also be influenced by other factors. For example, in Nigeria rainfall, currency exchange rate, and food exports are the most important factors driving agricultural output. Food importation, diversion of funds for agriculture, and low penetration of agricultural technology were identified as the major constraints to agricultural development in Nigeria [5].

Other studies reach the same results, in which increasing agricultural research and development expenditures will support agricultural economic growth [6-9]. However, increasing fiscal spending on agriculture, while promoting agricultural growth, can also impact the quality of agroecosystems [10]. Soil and water conservation has a significant impact on the per capita income of rural households in China [11].

To achieve sustainable long-term growth in agriculture, we need to strengthen reforms and innovation in the rural economic system [12]. In the long run, a land system that is compatible with the country's macroeconomic condition has a positive contribution to China's agricultural economic growth $[13,14]$. Studies in Commonwealth of Independent States (CIS) countries have shown that policy factors such as land reform contribute, to some extent, to the growth of agricultural production [15]. Studies in the EU countries show that the average farm income is already close to the average non-farm income, thanks to the Common Agricultural Policy (CAP) support [16]. Agricultural policies are important for poverty reduction and agricultural development [17-22]. On the contrary, distorted agricultural policies can hinder its agricultural development [23]. Effective monetary and fiscal policies can boost agricultural growth over time [24-26].

The studies above focus on the different factors that are related to agricultural growth, but few scholars have analyzed the historical trajectory of agricultural growth in depth. As a reflection of China's economic growth, agricultural growth has shown up-and-down cycles over the past 20 years. This is despite China's high rate of macroeconomic growth and strong support from the government's pro-agricultural policies.

Recent studies on agricultural economic cycles in Spain, Cuba, and the United Kingdom identified the causative factors driving these cycles. Studies in the Spanish regional economy show that the agricultural production cycle is constrained by the natural environment and ecological conditions, meanwhile, at the same time, benefitted from rapid economic and social development and globalization [27]. The history of agricultural development in Cuba indicates that, according to the theory of the adaptive renewal cycle, the process of agricultural development is nonlinear and is divided into four stages: Growth, maturation, collapse, and transformation [28]. Studies on the United Kingdom agriculture shows that agriculture sustainably reinforces cultural management and ecosystems and will affect cultural service assets in a broad sense [29].

Since 1952, China's agricultural economic cycle has fluctuated several times, with three classical economic cycles and three growth cycles. The agricultural economies have achieved growth and development in the midst of cyclical fluctuations, and responded to the economic policies and institutional reforms in different economic periods [30]. Changes in China's agricultural policies are the main cause of agricultural fluctuations. Institutional factors are important causes of the cyclical fluctuations of the agricultural economy [31]. The pricing mechanism and land system can promote the change of the agricultural economy to a high-growth state [32].

The magnitude of fluctuations in China's agricultural economic cycle has declined significantly and China's agricultural development has gradually stabilized from the 1980s. Overall, China's agricultural economic cycle has a high frequency of fluctuations with small magnitude [33]. China's agricultural economy is characterized by significant inertia during low-growth rates. When the agricultural growth rate is relatively high, its risk of shocks is higher, as well. When the growth rate is relatively low, its uncertainty is relatively low [34]. Agricultural economic cycles have certain spatial correlations and will amplify agricultural economic fluctuations through cyclical spatial spillover, forming cyclical synergistic effects [35]. Technological and institutional innovations in China should emphasize more on sustainable development which considers the relationship between agriculture 
and the environment, rather than setting inconsistent and sometimes incompatible policy goals from different perspectives [36].

Agricultural policies implemented by the Chinese government have raised farmers' income levels and contributed to long-term food security goals. However, such policies have also led to a price gap between domestic and international markets for agricultural products leading to a sharp increase in agricultural imports and the accumulation of large stocks [37]. Previous experience in developing agriculture through institutional reform, technological change, market reform, and investment in agriculture remains the key to future success in ensuring food security and sustainable agriculture growth in China [38]. The true family farm of moderate "small and precise" scale, which has emerged quite widely in China over the past 30 years, can chart a more sustainable way forward for Chinese agriculture [39].

Agricultural economic growth should not come at the cost of damage to natural resources and pollution of the ecological environment, but should focus on the coordination and balance between the short- and long-term [2]. Environmentally friendly technological innovation is a long-term driving force for both the development and sustainable growth of agricultural economies. On the whole, every $1 \%$ increase in environmentally friendly agricultural technology innovation causes a $0.375 \%$ increase in agricultural economic growth, while every $1 \%$ increase in the extent of environmentally friendly technology diffusion causes a $0.542 \%$ increase in agricultural economic growth [40].

Attention should be paid to the phenomenon of decreasing ecological land use in the agro-pastoral zone, and the land use structure should be adjusted to provide good ecological conditions for the sustainable development of the agricultural economy in the agro-pastoral zone [41]. Soil and water conservation can contribute to agricultural economic growth and rural poverty reduction in China. Soil quality and capital inputs are now more important than farmland size and agricultural labor in poverty reduction and economic growth. Governments and farmers need to prioritize investments in soil and water conservation to boost the agricultural economy and reduce rural poverty [11]. As the use of linear measures does not allow for effective measurement of the characteristics of economic cycles, such as those found in agriculture, scholars have proposed various nonlinear econometric models to characterize the variability of economic cycles in detail, such as the Smoothed Migration Autoregressive (STAR) model, the Markov transfer (MS) model, and Threshold Autoregressive (TAR) models [42-44]. In recent years, researchers have measured the economic cycles of South Africa, Brazil, Turkey, etc. using Markov regime transfer models [45-47].

On this basis, in the existing studies on the fluctuation dynamics of the Chinese economic cycle, scholars have quantitatively measured the economic cycle based on different forms of Markov transfer (MS) models to analyze the dynamic characteristics of the economic cycle when it varies across regimes [48-50]. Sui Jianli and Song Diandian first used a Markovian regime shift model to study the Chinese agricultural economic cycle, but he chose a two-regimes Markovian shift model that could only distinguish the Chinese agricultural economic cycle into a high-growth and a low-growth regime [51].

This paper follows the previous research path but differs in that the time domain of this paper is placed in the specific context of the Chinese government's annual agricultural policies to support agricultural development from the early 21st century. Our research focuses on China's agricultural economic development under the support of agricultural policies. In this paper, we construct a Markov transfer model with three regions to analyze the agricultural development in China since 2001 and use it to initially assess the effects of agricultural policies during this period.

In addition, a nonlinear MS (M)-Autoregressive Process (AR) (p) model with "mean form" and "intercept form" was created, and the growth rate of the overall agricultural product is included in our study. The nonlinear model with the "mean form" focuses on capturing the trajectory of the mean levels as they shift across time, while the nonlinear model with the "intercept form" is able to track the dynamic path of time series means 
since they smoothly transition over time as they shift by regime. The model is able to more accurately and sharply capture the cyclical fluctuations in the mean of each variable's time series data. Drawing on the ideas of Krolzig, this paper provides a quantitative demonstration of the growth dynamics in the context of policy support for China's agricultural economy [52]. The specific contribution of this paper to the scientific literature on agricultural development is to empirically highlight the importance of agricultural policy for agricultural development.

The Markov transfer model has the advantage of being able to accurately distinguish the dynamic changes between different variables, which is different from other models. Therefore, the Markov transfer model is used in this paper to study the growth of China's agricultural economy. In order to accurately understand the cyclical evolutionary path of the agricultural economy, this paper takes not only the total agricultural output as the object of study, but also the total output of agriculture, forestry, fishery, and animal husbandry sub-sectors of Chinese agriculture.

\section{Methods and Materials}

\subsection{Nonlinear MS (M)-AR ( $p$ ) Model Construction and Model Estimation}

In this paper, we model the growth rates of China's agriculture, forestry, livestock, fisheries, and overall agriculture, respectively, and its regime shifts. The growth rate is measured as $y_{t}$ and the regime shift in the growth rate is measured as $s_{t}$. We consider a linear p-order Autoregressive Process (AR) as the starting point for the nonlinear model:

$$
y_{t}=v+A_{1} y_{t-1}+\ldots+A_{p} y_{t-p}+u_{t}
$$

where $v$ is chosen as the intercept term. In addition, this paper requires the necessary assumptions regarding the smoothness of the $y_{t}$ time series. In the equation $1-A_{1} L-A_{2} L^{2}-\cdots-A_{p} L^{p}=0$ of the lag operator $L$, we assumed that the characteristic roots of the equation are located outside the unit circle. We also assumed that the error term $u_{t}$ of Equation (1) follows the standard normal distribution, i.e., $u_{t} \sim N I D(0, \Sigma)$. Based on these assumptions, the model form presented in Equation (1) is the "intercept form" of the classical AR $(p)$ model. The "mean value form" of the linear p-order AR $(p)$ model is presented as follows:

$$
y_{t}-\mu=A_{1}\left(y_{t-1}-\mu\right)+\ldots+A_{p}\left(y_{t-p}-\mu\right)+u_{t}
$$

In this paper, $\mu$ is defined as the mean of the time series $y_{t}$ for each variable. We can clearly see that the linear AR $(p)$ models in "intercept form" and "mean form" constructed in the previous section have limitations in detailing the possible $y_{t}$ nonlinear features in the time series and cannot successfully capture the "structural mutations" embedded in the time series. In light of this, we explored in depth the "structural mutation" phenomenon in China.

This paper follows the approach of Hamilton and Krolzig [43,52] to add random $s_{t}$ variables to the time series $y_{t}$ to deeply explore the potential nonlinear "Markovian shifts" in China's agricultural economic growth process, where M different regimes $s_{t}$ can be characterized, $s_{t} \in\{1, \ldots, M\}$. By introducing $s_{t}$ into the time series data generation process, we are able to more accurately examine the dynamic changes in the nonlinear AR $(p)$ model. At the same time, this paper further assumes $s_{t}$ that it is possible for the Markov process to be followed to traverse all $M$ regimes, based on which, the specific transfer matrix can be expressed in the following form:

$$
P=\left[\begin{array}{cccc}
P_{11} & P_{12} & \cdots & P_{1 M} \\
P_{21} & P_{22} & \cdots & P_{2 M} \\
\vdots & \vdots & \ddots & \vdots \\
P_{M 1} & P_{M 2} & \cdots & P_{M M}
\end{array}\right]
$$


In Equation (3), $p_{i j}=\operatorname{Pr}\left(s_{t+1}=j \mid s_{t}=i\right), \Sigma_{j=1}^{M} p_{i j}=1, \quad \forall i, j \in\{1, \ldots, M\}$.

In the following sections of this paper, we construct nonlinear MS $(M)$-AR $(p)$ models with reference to the "mean-form" linear AR $(p)$ models. The MSM $(M)$-AR $(p)$ model containing the variable parameter function $\mu\left(s_{t}\right)$ can be constructed by introducing the regime state variable $s_{t}$ into the mean $\mu$ shown in Equation (2).

$$
y_{t}-\mu\left(s_{t}\right)=A_{1}\left[y_{t-1}-\mu\left(s_{t-1}\right)\right]+\ldots+A_{p}\left[y_{t-p}-\mu\left(s_{t-p}\right)\right]+u_{t}, \quad u_{t} \sim \operatorname{NID}(0, \Sigma)
$$

It is known that

$$
\mu\left(s_{t}\right)= \begin{cases}\mu_{1}, & s_{t}=1 \\ \vdots & \vdots \\ \mu_{M}, & s_{t}=M\end{cases}
$$

The variable-parameter functions $A_{1}\left(s_{t}\right), \ldots, A_{p}\left(s_{t}\right), \Sigma\left(s_{t}\right)$, and, $v\left(s_{t}\right)$ have very similar expressions to $\mu\left(s_{t}\right)$ as defined above and, therefore, will not be repeated in the following section.

The average duration $D\left[s_{t}(i)\right]$ with regime variables $s_{t}$ using the following formula:

$$
D\left[s_{t}(i)\right]=E\left[s_{t}=i\right]=\frac{1}{1-p_{i i}}, i=1,2,3
$$

The unique approach of this paper is to create a nonlinear MS (M)-AR (p) model that includes both "mean form" and "intercept form." The nonlinear MS (M)-AR (p) model is further explored using the Expectation Maximization (EM) algorithm and the Maximum Likelihood (ML) technique [43,52].

When we use these nonlinear MS (M)-AR (p) models for economic analysis, we need to first verify the stationarity of the variable data. In this paper, we will use ADF (Augmented Dickey-Fuller) test, PP (Phillips-Perron) test, and KPSS (Kwiatkowski-Phillips-SchmidtShin) test to check the stability of the variable data. In addition, for the multiple nonlinear models created in this paper, it is necessary to calculate the AIC (Akaike Information Criterion), HQ (Hannan Quinn), and SC (Schwarz Criterion) values under different model settings according to the AIC information criterion, HQ information criterion, and SC information criterion to analyze the reliability and validity of the model.

\subsection{Data Selection for China's Agricultural Economic Growth}

Based on the quarterly data of China's gross product of agriculture, forestry, livestock, fishery, and overall gross agricultural product from Q1 2001 to Q1 2018, this paper further calculated the quarterly data of the growth rate of each variable to examine the cyclical dynamic change process of China's agricultural economic growth in detail. The growth rate is calculated by the year-on-year method and takes into account price inflation. The data in this paper were obtained from the China Economy Internet (CEI) data (http:/ / db.cei.cn, accessed on 24 May 2021) and the China Statistical Yearbook.

To further explore the dynamic paths of the growth rates of China's gross product of agriculture, forestry, livestock, fishery, and overall agricultural product over time, this paper uses the H-P filtering technique [52,53] to capture the trend component and the volatility component of the time series of each variable to provide a clearer picture of the dynamic evolution of the aggregate value of each variable within the time domain under study. Specifically, the "trend component" can clearly depict the trend state and the change process of each variable time series over a long period of time. The "volatility component" can more carefully depict the fluctuation magnitude and uncertainty of each variable time series data in different economic periods. The "volatility component" can provide a more detailed picture of the volatility and uncertainty of the time series of each variable in different economic periods. 


\section{Results}

\subsection{Growth Rate Dynamic Trajectory Analysis}

In this paper, we first depict the time fluctuation paths of the growth rates of the gross product value in China's agriculture, forestry, livestock, fishery, and agriculture industries. We can see that, on the one hand, the growth rates of the gross product value of China's agriculture, livestock, fishery, and agriculture time series have generally similar time dynamic trajectories, while the growth rates of China's forestry industry alone show relatively different trend changes (Figures 1-5). On the whole, the fluctuations and oscillations of the time series of the growth rates of the gross product value of China's agriculture, forestry, fishery, and agriculture are relatively small, while the fluctuations of the growth rate of the gross product value of China's livestock are more drastic—showing steep fluctuations with steep increases and decreases.

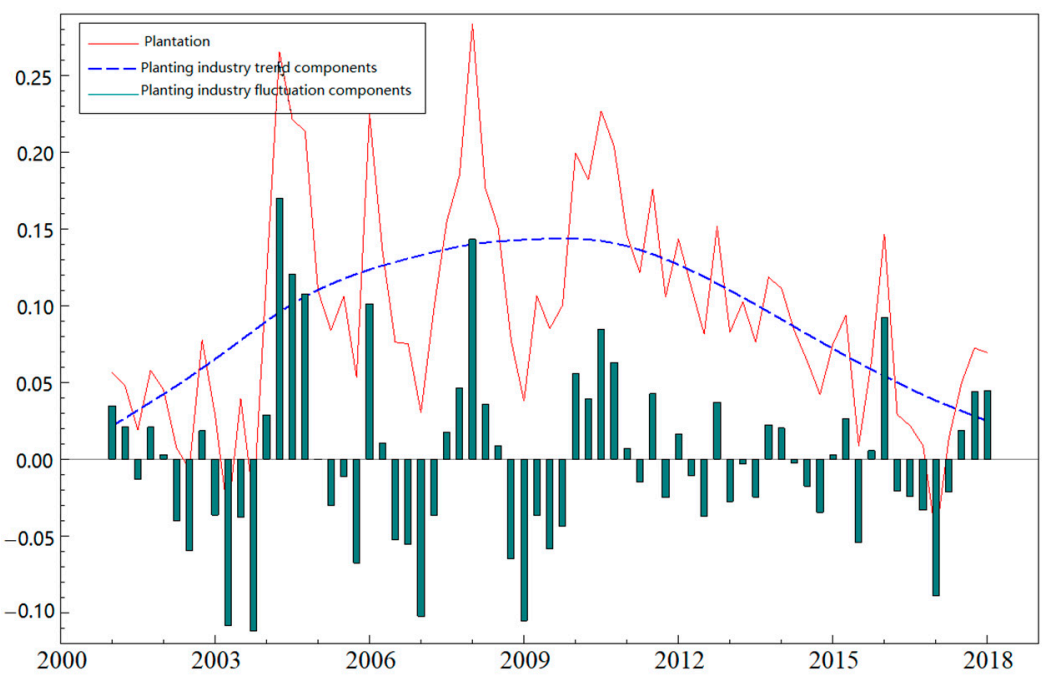

Figure 1. Time series of the growth rate of the gross agriculture product.

The "trend component" of the growth rate of China's gross agriculture product shows that China's agriculture started to achieve significant growth in the early 21st century and showed an increasing trend year by year, reaching its highest "peak" roughly around 2010 and declining from 2010-2018 (Figure 1). In addition, looking at the "fluctuating components" of the growth rate of China's gross agriculture product depicted in Figure 1, the growth rate of China's gross agriculture product has been characterized by weak fluctuations since 2010, with more significant fluctuations clustering in the sample interval before 2010. However, in recent years, the volatility of the growth rate of China's gross agriculture product has increased.

The "trend component" of the growth rate of China's gross forestry product as depicted shows that China's gross forestry product has generally grown steadily over the time horizon selected for this paper, rising year by year at the beginning of the 2000s and peaking in 2003 (Figure 2). Subsequently, the growth rate of the gross forestry product moves down from the "peak" at a very slow pace. In the rest of the sample period, the fluctuation of the growth rate of China's gross forestry product is small, and, especially in recent years, the fluctuation of the growth rate of China's gross forestry product is extremely weak. 


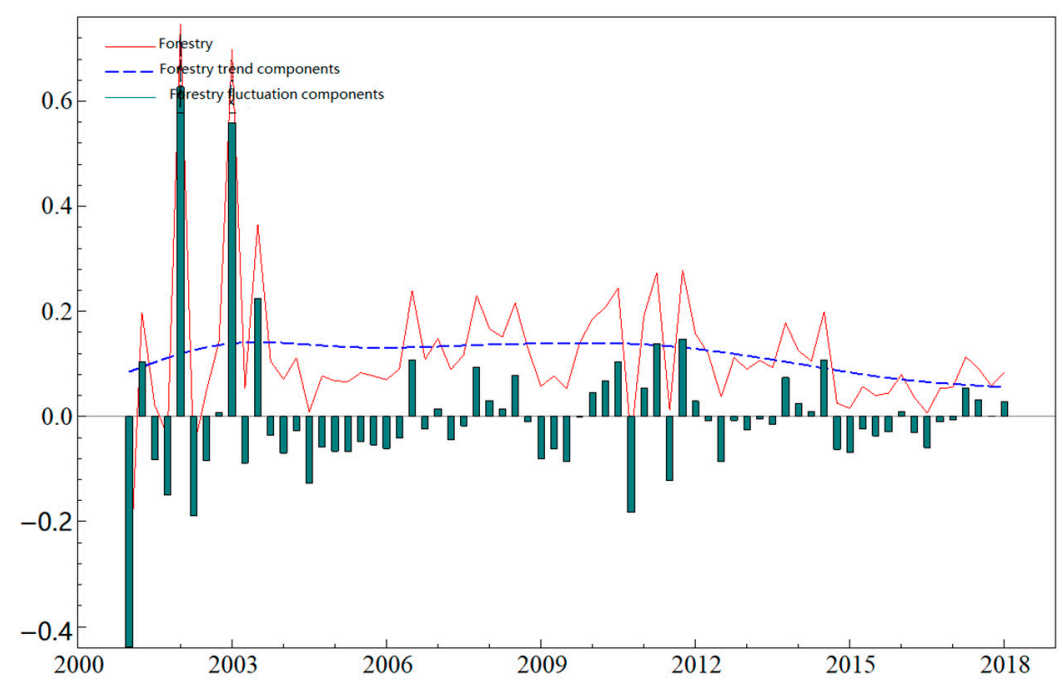

Figure 2. Time series of growth rate of the gross forestry product.

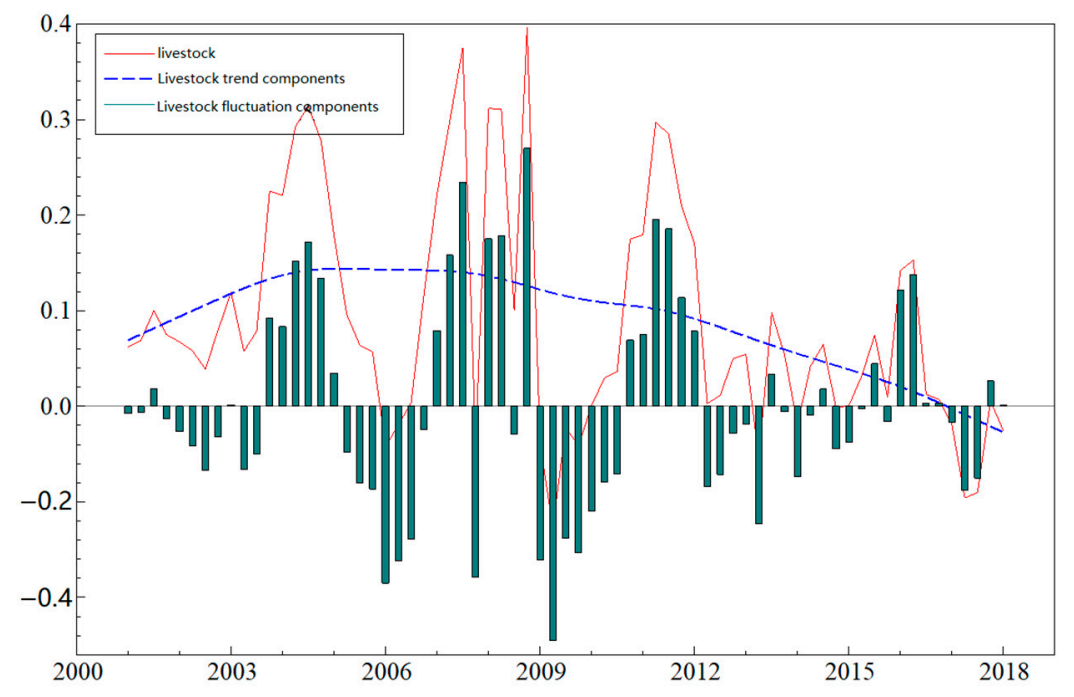

Figure 3. Time series of growth rate of the gross livestock product.

The "trend component" shown in Figure 3 shows that the growth rate of China's gross livestock product changes slowly and appears to hover between "peaks" and "troughs" several times. The growth rate of the gross livestock product in general gradually shifts downward, particularly in recent years. Industry livestock growth rates are lower than the initial levels during the early 21st century.

At the same time, the "fluctuation component" in Figure 3 reflects that the time series of the growth rate of China's gross livestock product contains significant fluctuation clustering characteristics, and shows higher fluctuation than the growth rate of gross product of agriculture, forestry, and fishery industries. In other words, there is relatively more volatility and uncertainty in the time series of the growth rate of China's gross product value of livestock. However, it is also clear that the volatility of the growth rate of China's gross livestock product has significantly decreased in the recent years. In recent years, the Chinese government has implemented policies to curb the development of animal husbandry in order to protect the environment, resulting in negative growth in the animal husbandry industry. 


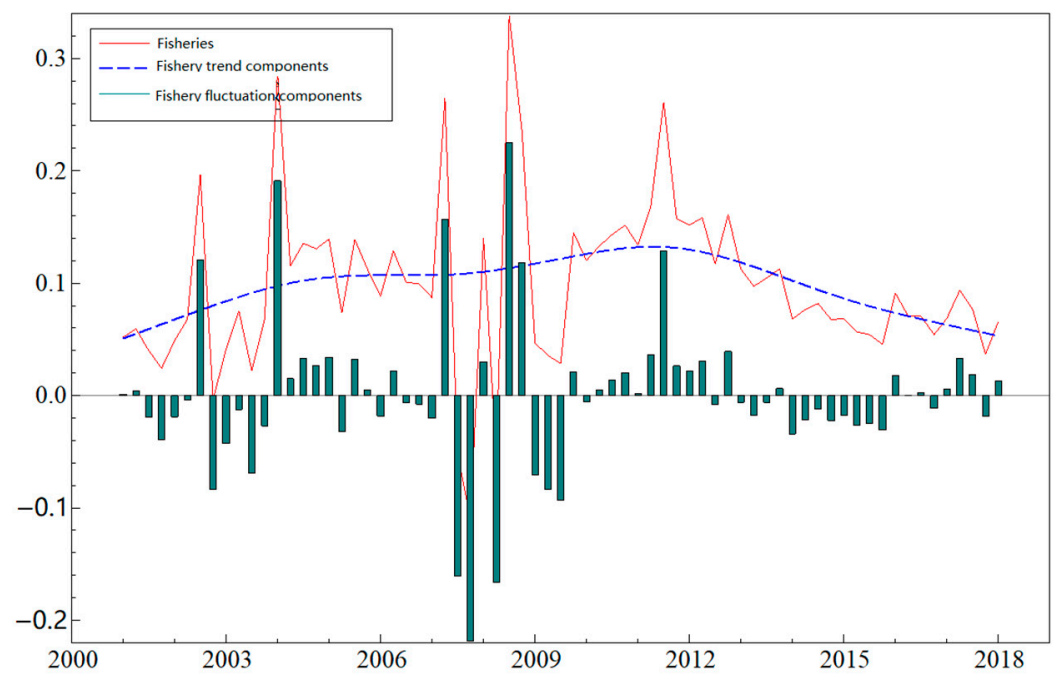

Figure 4. Time series of growth rate of the gross fishery product.

The dynamic trajectory of the growth rate of China's gross fishery product over time is shown in Figure 4. It can be seen from the "trend component" of the figure that, during the initial period in 2001, the growth rate of gross fishery product was at a low level. Subsequently, the growth rate of the gross fishery product shows a "cyclical-like" pattern of gradually climbing from a lower growth level to a higher "peak" level, and then slowly falling back to a lower "trough" level. In recent years, the growth rate of China's gross fishery product has been moving downward. In addition, the "volatility component" of the time series of the gross fishery product growth rate shows that during the global financial crisis from 2007 to 2010, China's gross fishery product growth rate exhibited a highly volatile clustering characteristic. However, in recent years, the volatility of China's gross fishery product growth rate has significantly weakened.

The growth rate of China's gross agricultural product for all four agricultural sectors aggregated together is depicted in Figure 5. Since 2001, this aggregated growth rate has shown a gradual increase in development momentum and, after reaching the highest "peak" in succession, has been declining. In addition, looking at the "fluctuating component" of the growth rate of China's agricultural product depicted in Figure 5, we can see that, since 2001, China's gross agricultural product has shown more obvious fluctuations and a certain clustering of fluctuations. During the subsequent period of 2012-2018, the volatility of the growth rate of China's gross agricultural product decreased.

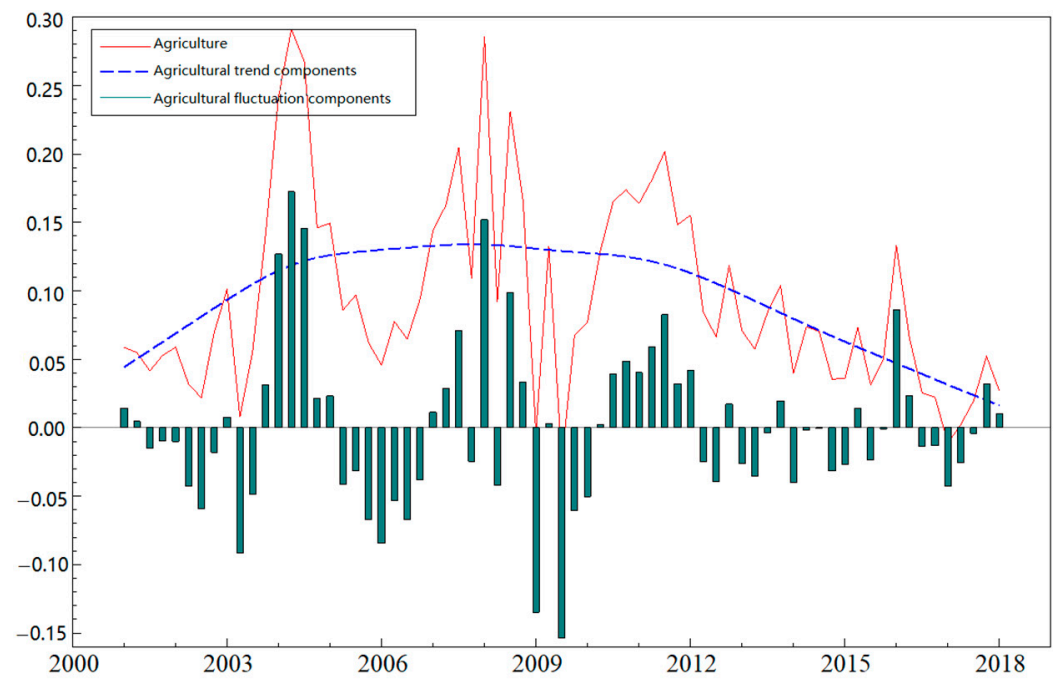

Figure 5. Time series of growth rate of the gross agricultural product. 


\subsection{The Parameter Estimation of the MSM (M)-AR ( $p)$ Model}

The growth rates of China's gross product of agriculture, forestry, livestock, fishery, and agriculture, depicted in Figures 1-5, can be used to make a preliminary visual judgment of the long-term dynamic changes in China's agricultural economy. The next part of this paper is based on a nonlinear MS (M)-AR (p) model with time series data on the growth rates of China's gross product of agriculture, forestry, livestock, fishery, and agriculture. The results show that the growth rates of China's gross product of agriculture, forestry, livestock, fishery, and overall agriculture were stationary at the $5 \%$ significance level, while the growth rates of all variables were first-order single integers at the $1 \%$ significance level.

The study shows that the AIC, HQ, and SC values of the time series of the growth rate of China's gross agriculture product were the smallest when the model was set to the MSM (3)-AR (3) form. The AIC, HQ, and SC values of the time series of the growth rate of China's gross forestry product were the smallest when the model was set to the MSM (3)-AR (1) form. The AIC, HQ, and SC values of the time series of the growth rate of China's livestock, fishery, and China's agricultural output are all minimized when the model is set in the form of MSM (3)-AR (4). Thus, it is reasonable and reliable to use the MSM (3)-AR (p) model constructed in this paper to investigate the dynamic evolution of China's agricultural economy in terms of the growth region system and its changing dynamics.

The parameter estimation results of the MSM (M)-AR (p) model calculated by different variables are presented in Tables 1 and 2, respectively. The results of the t-statistical test indicate that all values were significant at the $1 \%$ or $5 \%$ level, except for the growth rate of the total fishery output in the zone system $1\left(s_{t}=1\right)$. This indicates that the model we chose is appropriate. The mean $\mu$ estimates of the growth rates of the gross product of China's agriculture, forestry, livestock, fishery, and agricultural industries are all consistent with the parameter constraints $\mu_{1}<\mu_{2}<\mu_{3}$ (Tables 1 and 2). Therefore, the growth rates of each variable are considered as the low-growth regime, medium-growth regime, and rapid-growth regime for regime 1 , regime 2 , and regime 3 , respectively.

Table 1. MSM (3)-autoregressive process (AR) (p) model parameter estimation results.

\begin{tabular}{|c|c|c|c|c|c|c|c|c|}
\hline \multirow{2}{*}{ Regime } & \multicolumn{2}{|c|}{$\begin{array}{l}\text { Growth Rate of Gross } \\
\text { Agriculture Product }\end{array}$} & \multicolumn{2}{|c|}{$\begin{array}{l}\text { Growth Rate of Gross } \\
\text { Forestry Product }\end{array}$} & \multicolumn{2}{|c|}{$\begin{array}{l}\text { Growth Rate of Gross } \\
\text { Livestock Product }\end{array}$} & \multicolumn{2}{|c|}{$\begin{array}{l}\text { Growth Rate of Gross } \\
\text { Fishery Product }\end{array}$} \\
\hline & $\begin{array}{l}\text { Estimated } \\
\text { Value }\end{array}$ & $\begin{array}{l}\text { Standard } \\
\text { Deviation }\end{array}$ & $\begin{array}{l}\text { Estimated } \\
\text { Value }\end{array}$ & $\begin{array}{l}\text { Standard } \\
\text { Deviation }\end{array}$ & $\begin{array}{l}\text { Estimated } \\
\text { Value }\end{array}$ & $\begin{array}{l}\text { Standard } \\
\text { Deviation }\end{array}$ & $\begin{array}{l}\text { Estimated } \\
\text { Value }\end{array}$ & $\begin{array}{l}\text { Standard } \\
\text { Deviation }\end{array}$ \\
\hline$\mu_{1}$ & 0.0793 ** & 0.0362 & $0.0520^{* * *}$ & 0.0158 & $0.0277^{* *}$ & 0.0125 & 0.0217 & 0.0201 \\
\hline$\mu_{2}$ & $0.1334^{* * *}$ & 0.0510 & $0.1254^{* * *}$ & 0.0130 & $0.0809 * *$ & 0.0343 & $0.0802^{* * *}$ & 0.0144 \\
\hline$\mu_{3}$ & $0.2057^{* * *}$ & 0.0392 & $0.7102^{* * *}$ & 0.0501 & $0.2812 * * *$ & 0.0261 & $0.1685^{* * *}$ & 0.0205 \\
\hline$A_{1}$ & $0.3598^{* *}$ & 0.1643 & $-0.1339 * *$ & 0.0668 & $0.3666^{* * *}$ & 0.0732 & $-0.3219^{* * *}$ & 0.1190 \\
\hline$A_{2}$ & 0.0973 & 0.1808 & - & - & -0.1270 & 0.0829 & $-0.5408^{* * *}$ & 0.1085 \\
\hline$A_{3}$ & 0.1980 * & 0.1185 & - & - & $0.2104 * * *$ & 0.0728 & $-0.3489 * * *$ & 0.1116 \\
\hline$A_{4}$ & - & - & - & - & $-0.4658^{* * *}$ & 0.0684 & $-0.6732^{* * *}$ & 0.1074 \\
\hline
\end{tabular}

Table 2. Estimation results for each parameter of the MSM (3)-AR (p) model.

\begin{tabular}{ccc}
\hline \multirow{2}{*}{ Regime } & \multicolumn{2}{c}{ Growth Rate of Gross Agricultural Product } \\
\cline { 2 - 3 } & Estimated Value & Standard Deviation \\
\hline$\mu_{1}$ & $0.0617^{* *}$ & 0.0268 \\
\hline$\mu_{2}$ & $0.0764^{* * *}$ & 0.0274 \\
\hline$\mu_{3}$ & $0.1600^{* * *}$ & 0.0251 \\
\hline
\end{tabular}


Table 2. Cont.

\begin{tabular}{|c|c|c|}
\hline \multirow{2}{*}{ Regime } & \multicolumn{2}{|c|}{ Growth Rate of Gross Agricultural Product } \\
\hline & Estimated Value & Standard Deviation \\
\hline$A_{1}$ & $0.2081 * *$ & 0.0906 \\
\hline$A_{2}$ & $0.7292 * * *$ & 0.0975 \\
\hline$A_{3}$ & $0.2134^{* *}$ & 0.0990 \\
\hline$A_{4}$ & $-0.5313^{* * *}$ & 0.0868 \\
\hline
\end{tabular}

\subsection{The Dynamic Shift Probabilities of China's Agricultural Growth Regime}

Based on the time series data of the growth rates of total output value of Chinese agriculture, forestry, livestock, fishery and overall agricultural in China, we calculated the dynamic shift probabilities of China's agricultural economic growth regimes using Equation (3). The results are presented in Tables 3-7, respectively. We can see that the probability of staying at a low-growth rate for the agriculture sector is $0.9133\left(p_{11}=0.9133\right)$, and the probability of shifting to the medium or fast growth range is very low, corresponding to $\mathrm{A}$ and $\mathrm{B}$, which respectively, indicates that the agriculture sector is likely to maintain a low-growth state (Table 3). The probability of staying in the medium-growth range for agriculture is only 0.0548 , while the probability of shifting to the low-growth range is as high as $0.9452\left(p_{21}=0.9452\right)$, and there is almost no possibility of shifting to the high-growth range. This reinforces the high probability of maintaining a low-growth rate for the agriculture sector.

The probability of maintaining a high-growth range for the agriculture is relatively high at $0.5588\left(p_{33}=0.5588\right)$, but the probability of falling back to a medium-growth state is also relatively high (0.4421). Since the probability of agriculture maintaining the medium-growth state is very low and the probability of shifting to the low-growth state is very high $0.9452\left(p_{21}=0.9452\right)$, the probability of falling back from the fast-growth state to the medium-growth state through the medium-growth state to the low-growth state is also very high. Again, the result shows that the probability of maintaining the low-growth rate in the agriculture sector is high.

Overall, the probability of staying at the low-growth state for the agriculture sector is very high, while the probability of shifting to the medium or fast rate range is very low. Moreover, the probability of falling from a medium to a low-speed state and of falling from a fast state to a low-speed state through a medium-speed state is very high. Therefore, agriculture in China clearly tends to maintain a low-growth rate.

Table 3. Transfer probability matrix of the regime for the growth rate of the gross agriculture product.

\begin{tabular}{cccc}
\hline & $\begin{array}{c}\text { Low-Growth } \\
\text { Regime }\end{array}$ & $\begin{array}{c}\text { Medium-Growth } \\
\text { Regime }\end{array}$ & $\begin{array}{c}\text { Rapid-Growth } \\
\text { Regime }\end{array}$ \\
\hline Low-growth regime & 0.9133 & $<0.0001$ & 0.0867 \\
\hline Medium-growth regime & 0.9452 & 0.0548 & $<0.0001$ \\
\hline Rapid-growth regime & $<0.0001$ & 0.4421 & 0.5588 \\
\hline
\end{tabular}

The probability of forestry maintaining the low and medium speed states are both very high at $0.8937\left(p_{11}=0.8937\right)$ and $0.9774\left(p_{22}=0.9774\right)$, respectively, and the probability of shifting to other states is very small (Table 4 ). The probability of maintaining forestry in the fast-growth state is close to zero, while the probability of shifting to the low and medium speed states is very high, $0.6109\left(p_{31}=0.6109\right)$ and $0.3891\left(p_{32}=0.3891\right)$, respectively. This indicates that forestry will likely maintain a low to medium-growth state and has the highest probability of staying in the medium-growth state. 
Table 4. Transfer probability matrix of the regime of the growth rate of the gross forestry product.

\begin{tabular}{cccc}
\hline & $\begin{array}{c}\text { Low-Growth } \\
\text { Regime }\end{array}$ & $\begin{array}{c}\text { Medium-Growth } \\
\text { Regime }\end{array}$ & $\begin{array}{c}\text { Rapid-Growth } \\
\text { Regime }\end{array}$ \\
\hline Low-growth regime & 0.8937 & 0.0007 & 0.1056 \\
\hline Medium-growth regime & 0.0226 & 0.9774 & $<0.0001$ \\
\hline Rapid-growth regime & 0.6109 & 0.3891 & $<0.0001$ \\
\hline
\end{tabular}

The probability of maintaining a low-growth state in the livestock sector is very high $0.9063\left(p_{11}=0.9063\right)$, while the probability of shifting to either the medium or high growth range is low $0.0937\left(p_{12}=0.0937\right)$ and close to zero, respectively (Table 5). Therefore, it is relatively easy for the livestock industry to maintain a low-growth range. At the same time, the probability that the livestock sector maintains a fast-growth state is relatively high $0.6609\left(p_{33}=0.6609\right)$, but the probability of maintaining a medium-growth range is very low.

Table 5. Transfer probability matrix of the regime of the growth rate of the gross livestock production.

\begin{tabular}{cccc}
\hline & $\begin{array}{c}\text { Low-Growth } \\
\text { Regime }\end{array}$ & $\begin{array}{c}\text { Medium-Growth } \\
\text { Regime }\end{array}$ & $\begin{array}{c}\text { Rapid-Growth } \\
\text { Regime }\end{array}$ \\
\hline Low-growth regime & 0.9063 & 0.0937 & $<0.0001$ \\
\hline Medium-growth regime & 0.3023 & 0.0066 & 0.6911 \\
\hline Rapid-growth regime & 0.1461 & 0.1930 & 0.6609 \\
\hline
\end{tabular}

The probability of shifting China's total fishery output from the low-growth range to the medium-growth range and the fast-growth range is $p_{12}=0.5515$ and $p_{13}=0.4464$, respectively. The probability of maintaining a particular growth rate is highest sustaining fast-growth $\left(p_{33}=0.8026\right)$ followed by keeping at medium $\left(p_{22}=0.7345\right)$ and low $\left(p_{11}=0.0020\right)$ growth (Table 6$)$. It can be seen that the probability of maintaining the total fishery output value in the low-growth range is very low, and it is easy to climb from the low-growth state to the medium- and high-growth state. There is a high probability of maintaining the medium-growth state and high-growth state, and it is easy to maintain the medium- and high-growth state, so China's fishery industry has a very good developmental trend.

The probability of transferring China's total fishery output value from the mediumgrowth regime back to the low-growth regime is $p_{21}=0.2646$, and the probability of transferring from the fast-growth regime to the medium-growth regime is $p_{32}=0.1974$. The probability of shifting from the "fast-growth regime" to the "medium-growth regime" is close to zero. Therefore, the probability of shifting from a higher growth state to a lower growth state is low, which indicates a more stable development trend of fisheries.

Table 6. Transfer probability matrix of regimes for the growth rate of the gross fishery product.

\begin{tabular}{cccc}
\hline & $\begin{array}{c}\text { Low-Growth } \\
\text { Regime }\end{array}$ & $\begin{array}{c}\text { Medium-Growth } \\
\text { Regime }\end{array}$ & $\begin{array}{c}\text { Rapid-Growth } \\
\text { Regime }\end{array}$ \\
\hline Low-growth regime & 0.0020 & 0.5515 & 0.4464 \\
\hline Medium-growth regime & 0.2646 & 0.7345 & 0.0009 \\
\hline Rapid-growth regime & $<0.0001$ & 0.1974 & 0.8026 \\
\hline
\end{tabular}

From the results of the transfer probability matrix of China's gross agricultural product, the maintaining probabilities of the low-, medium-, and rapid-growth regime of the gross agricultural product are $p_{11}=0.8425, p_{22}=0.5909$, and $p_{33}=0.8020$, respectively (Table 7). This indicates that China's gross agricultural product does not easily change its growth 
status when it is in different regimes, and it has certain inertia characteristics. When China's gross agricultural product is in the low-growth regime, it does not easily change to a higher growth rate, but when the level of agricultural development increases significantly, the gross agricultural product easily stays in the medium-growth regime and the rapid-growth regime and does not decline significantly.

It is clear that the probability of gross agricultural product climbing from the lowgrowth regime to the medium-growth regime is low $\left(p_{12}=0.1575\right)$, and essentially does little to possibly jump from the low-growth regime to the rapid-growth regime, while the probability of transferring the gross agricultural product from the medium-growth regime to the rapid-growth regime is relatively high $\left(p_{23}=0.3999\right)$. Thus, when the gross agricultural product is in the low-growth regime, it is difficult to achieve a significant increase due to the limitation of resources and technical facilities. When the gross agricultural product is in the medium-growth regime, the existing capital and technology advantages can be fully utilized to achieve a smooth transition from the medium-growth regime to the rapid-growth regime. The rise from the medium-growth regime to the rapid-growth regime is smooth.

The probability of change of China's gross agricultural product falling back from the medium-growth regime is $p_{21}=0.0092$, while the probability of change from the fastgrowth regime to the low-growth regime is relatively low $\left(p_{31}=0.1980\right)$. At the same time, the probability of change of gross agricultural product falling back from the rapid-growth regime to the medium-growth regime is close to zero. Thus, it is clear that the probability of a decline in gross agricultural product from the medium-growth regime is not high, and the gross agricultural product has a relatively stable development trend. In addition, when the gross agricultural product is in the rapid-growth regime, it does not decrease to the medium-growth regime. Therefore, the national strategy of modernizing agricultural development has achieved significant results during the sample period.

The overall improvement of China's agricultural production conditions and mechanization level in recent years has laid a good foundation for the development of agricultural facilities. Coupled with the Chinese government's rational planning and allocation of resources and active financial support policies, China's agricultural production modernization level has maintained steady and rapid growth. China's existing agricultural policies have achieved positive results.

Table 7. Transfer probability matrix of growth rate regime of China's gross agricultural product.

\begin{tabular}{cccc}
\hline & $\begin{array}{c}\text { Low-Growth } \\
\text { Regime }\end{array}$ & $\begin{array}{c}\text { Medium-Growth } \\
\text { Regime }\end{array}$ & $\begin{array}{c}\text { Rapid-Growth } \\
\text { Regime }\end{array}$ \\
\hline Low-growth regime & 0.8425 & 0.1575 & $<0.0001$ \\
\hline Medium-growth regime & 0.0092 & 0.5909 & 0.3999 \\
\hline Rapid-growth regime & 0.1980 & $<0.0001$ & 0.8020 \\
\hline
\end{tabular}

\subsection{Estimated Average Duration of Each Regime of China's Agricultural Economy}

We calculated the average durations of the growth rates of China's agriculture, forestry, livestock, fisheries, and overall agriculture for each growth rate (Table 8). Combining the maintenance probabilities given in Tables 3-7, and considering the average duration presented in Table 8, we further examined the dynamic characteristics of the variables in different regimes. The probability that China's gross agriculture product is in the lowgrowth regime is $p_{11}=0.9133$ maintained with an average duration of 11.54 quarters. This indicates that the lower level of development of the agriculture is more inclined to maintain a low rate of growth and will not make a significant leap to a state of rapid growth.

At the same time, the probability of maintaining a fast-growth state for the gross agriculture product is $p_{33}=0.5588$, and 2.27 quarters of average duration. The gross agriculture product can be stabilized in the rapid-growth regime with a moderate probability of maintenance in the short-term. When the gross agriculture product is in the 
medium-growth regime, the maintenance probability is $p_{22}=0.0548$ with an average duration of 1.06 quarters. The probability and average duration of sustaining agriculture in the medium-growth regime are low. Overall, China's agriculture is most likely to remain in the low-growth regime and is the least likely to be in the medium-growth regime among all regimes.

The probability that China's gross forestry product is in the low-growth regime is $p_{11}=0.8937$ with an average duration of 9.41 quarters and has the inertia characteristic of maintaining a low-growth rate. The probability of maintaining the medium-growth rate of forestry product is higher $p_{22}=0.9774$ with an average duration of 44.19 quarters, and the gross forestry product tends to maintain the medium-growth regime. The probability of maintaining the forestry product in the rapid-growth regime is close to zero with an average duration of 1.00 quarter. On balance, the gross forestry product tends to maintain a medium-growth rate over a longer time horizon, with a possible shift to a low-growth regime but a difficult shift to a rapid-growth regime.

The probabilities of maintaining medium- and fast-growth in the gross livestock product are $p_{22}=0.0066$ and $p_{33}=0.6609$ with 1.01 and 2.95 quarters of average duration, respectively. The probability that the gross product of livestock is in the low-growth regime is the highest among all regimes $\left(p_{11}=0.9063\right)$ and has an average duration of 10.67 quarters. Overall, the gross product of the livestock sector is more likely to remain in the low-growth regime, the least likely to remain in the medium-growth regime, and moderately likely to be in the rapid-growth regime.

The probability of maintaining low growth in China's gross fishery product was the lowest among all regimes $\left(p_{11}=0.0020\right)$ and only showed an average duration of 1.00 quarter. The probabilities of maintaining medium- and rapid-growth rates were $p_{22}=0.7345$ and $p_{33}=0.8026$, with 3.77 and 5.07 quarters average duration, respectively. This indicates that the gross fishery product is more likely to achieve medium- and highgrowth rates and has the highest probability of being in a fast-growth state and the lowest probability of being in a low-growth state.

Table 8. Estimated average duration of each regime (quarters).

\begin{tabular}{cccccc}
\hline Regime & $\begin{array}{c}\text { Gross Agriculture } \\
\text { Product } \\
\text { Growth Rate }\end{array}$ & $\begin{array}{c}\text { Gross Forestry } \\
\text { Product } \\
\text { Growth Rate }\end{array}$ & $\begin{array}{c}\text { Gross Livestock } \\
\text { Product Growth } \\
\text { Rate }\end{array}$ & $\begin{array}{c}\text { Gross Fishery } \\
\text { Product } \\
\text { Growth Rate }\end{array}$ & $\begin{array}{c}\text { Gross Overall } \\
\text { Agricultural Product } \\
\text { Growth Rate }\end{array}$ \\
\hline $\begin{array}{c}\text { Low-growth } \\
\text { regime }\end{array}$ & 11.54 & 9.41 & 10.67 & 1.00 & 6.35 \\
\hline $\begin{array}{c}\text { Medium-growth } \\
\text { regime }\end{array}$ & 1.06 & 44.19 & 1.01 & 3.77 & 2.44 \\
\hline $\begin{array}{c}\text { Rapid-growth } \\
\text { regime }\end{array}$ & 2.27 & 1.00 & 2.95 & 5.07 & 5.05 \\
\hline
\end{tabular}

The average duration of the gross agricultural product in the low-growth regime was relatively long, with an average duration of 6.35 quarters, while the average duration in the rapid-growth regime was also relatively long (Table 8). However, the average duration in the medium-growth regime was relatively short, at 2.44 quarters. At the same time, the probability that China's gross agricultural product will remain in the low-growth regime and rapid-growth regime was high $\left(p_{11}=0.8425, p_{33}=0.8020\right)$, and the probability of medium-growth was lower $\left(p_{22}=0.5909\right)$. This indicates that China's gross agricultural product is more likely to be in the low-growth regime and rapid-growth regime, and less likely to be in the medium-growth regime.

\subsection{Filter Probability and Smoothing Probability}

In the next section, the dynamic paths of the time series trajectories of the growth rates of each variable are clarified by depicting the smoothed probabilities of the gross 
product value of China's agriculture, forestry, livestock, fishery, and overall agriculture industries in each growth regime. In the smoothed probabilities of the low-growth regime (probability of $s_{t}=1: \operatorname{Pr}\left(s_{t}=1 \mid \xi_{t \mid t}\right)>0.5$ ), medium-growth regime (probability of: $s_{t}=2: \operatorname{Pr}\left(s_{t}=2 \mid \xi_{t \mid t}\right)>0.5$ ), and rapid-growth regime (probability of $s_{t}=3$ : $\left.\operatorname{Pr}\left(s_{t}=3 \mid \xi_{t \mid t}\right)>0.5\right), \xi_{t \mid t}$ refers to all information sets based on past $t$ periods.

The growth rates of China's gross product of agriculture, forestry, livestock, fishery, and overall agricultural industries changed frequently and dynamically among various regimes during the development of China's agricultural economic growth, and the dynamic paths of the growth rates of each variable in each regime will be further detailed in this paper. Within the sample interval studied, the gross agriculture product was in the rapidgrowth regime during (a) Q2 to Q4 2004, (b) Q1 2006, (c) Q4 2007 to Q1 2008, and (d) Q1 to Q4 2010 (Figure 6). Looking back at history, it is easy to see that these particular timeframes correspond to the launch of relevant policies in China (Appendix A, Table A1). For example in 2004, the first "Document No. 1" of the century was issued, which introduced the "three subsidies" policy, namely "direct subsidies for farmers, subsidies for good seeds, and subsidies for the purchase of agricultural machinery, and minimum purchase price for rice."

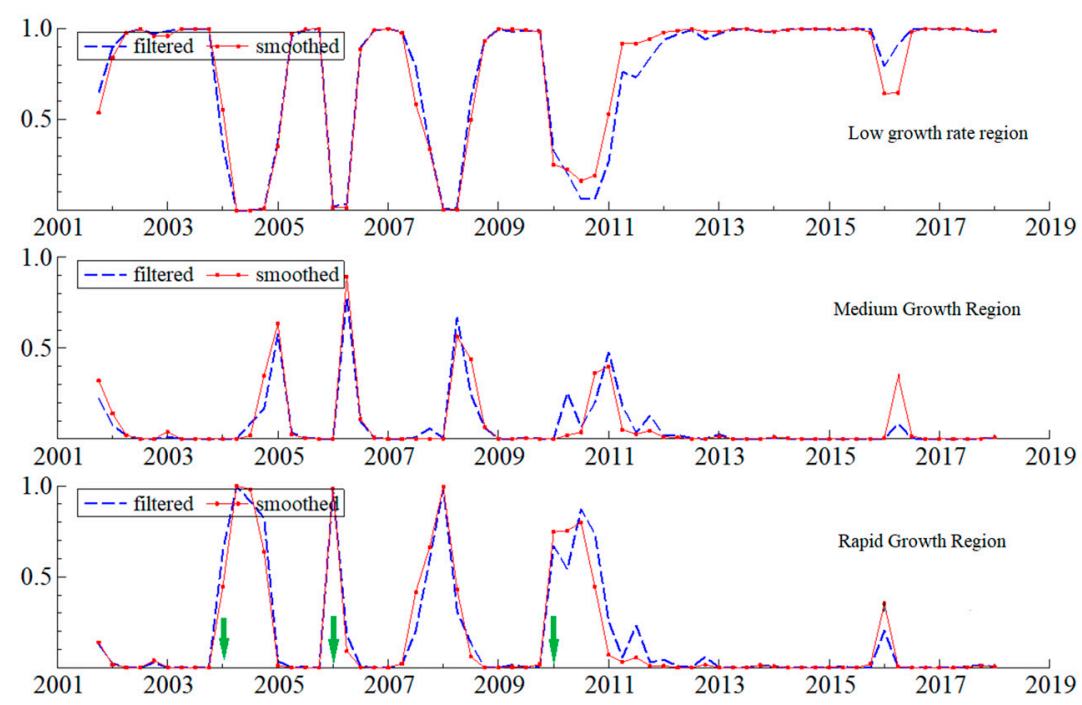

Figure 6. Filter probability and smoothing probability of gross agriculture product located in different growth regimes. Note: The green arrows mark the times when important policies were introduced.

In 2006, China completely abolished all agricultural taxes except the tobacco tax nationwide. In 2009, the Chinese government implemented the property rights policy of giving farmers fuller and more secure rights to contracted land management, and indicated that the existing land contract relationship would remain stable and unchanged for a long time. This injected confidence and vitality into the agricultural economy. In 2010, the government clearly proposed to give full play to the effective allocation of resources to promote agricultural development, and to improve the efficiency of agricultural development by improving the allocation of resource factors.

Under a series of effective policy measures, China's agriculture has achieved remarkable results and has been in the rapid-growth regime for a long period of time. However, China's gross agriculture product still fell into the medium-growth regime during Q1 2005, Q2 2006, and Q2 2008. It was in the low-growth rate during the periods from (a) Q4 2001 to Q1 2004, (b) Q2 to Q4 2005, (c) Q3 2006 to Q3 2007, (d) Q3 2008 to Q4 2009, and (e) Q1 2011 to Q1 2018.

Overall, we found that China's gross agriculture product generally fluctuated between the rapid-growth regime and the medium-growth regime but was able to maintain a 
relatively stable growth rate when it was in the low-growth regime. However, when in the low-growth regime, the growth rate remained relatively stable and had a more consistent smoothing probability. In the time domain selected in this paper, the gross agriculture product in the low-growth regime basically coincided with the occurrence of natural disasters, such as floods and snowstorms.

This judgment is consistent with the phenomena revealed in Tables 3 and 8 . That is, it is difficult for China's gross agriculture product to remain in the rapid-growth regime or medium-growth regime in general, but it tends to stay in the low-growth regime. Unlike prior literature, the model in this paper captures the rapid-growth regime of Chinese agriculture around 2006 and 2008, suggesting that the model in this paper is more accurate in modeling real fluctuations in economic development.

We can see from Figure 7 that in the early part of this century, China's agricultural development, including forestry, was greatly affected by the soft landing of China's macroeconomics. In the case of forestry, the gross forestry product showed more dramatic fluctuations at the beginning of the 20th century, with more frequent cyclical fluctuations. Coupled with the sudden impact of natural disasters on forestry development, the process of change in gross forestry product showed a direct fall from the rapid-growth regime to the low-growth regime and was less often in the medium-growth regime.

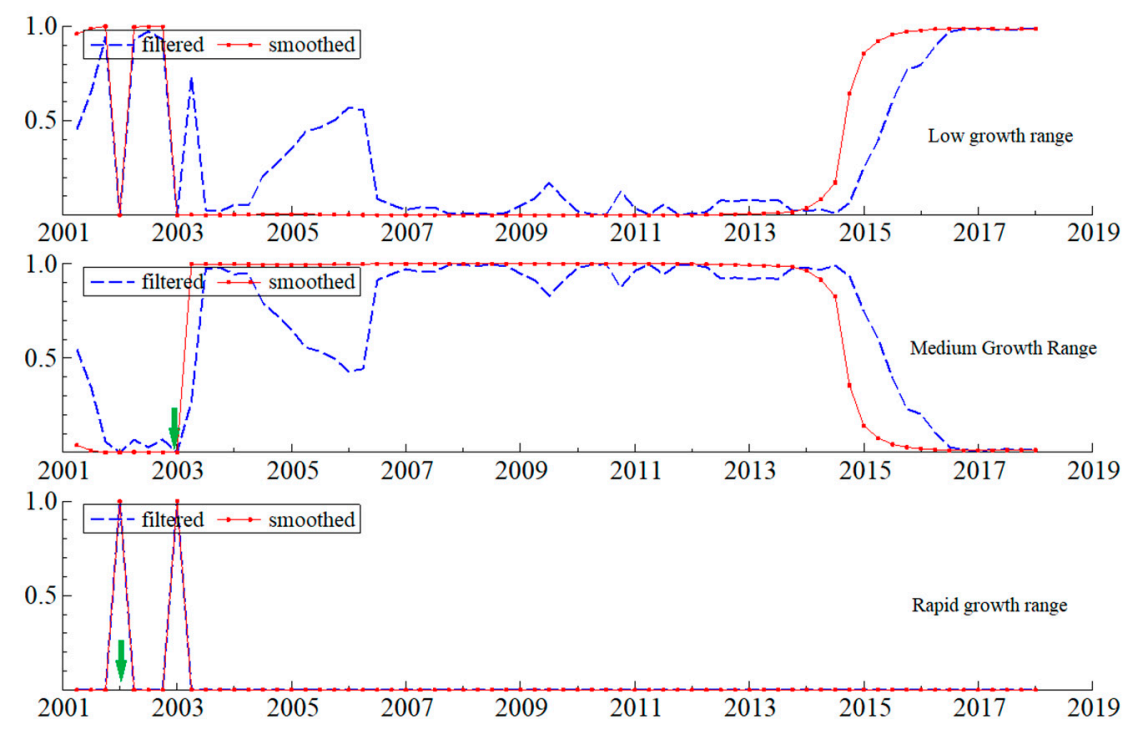

Figure 7. Filter probability and smoothing probability of gross forestry product located in different growth regimes. Note: The green arrows mark the times when important policies were introduced.

During the periods from Q2 2001 to Q4 2001 and Q2 2002 to Q4 2002, China's gross forestry product was in the low-growth regime, and, during Q1 2002 and Q1 2003, China's gross forestry product was in the rapid-growth regime. In 2002, the Chinese government promulgated the Regulations on Returning Farmland to Forestry to promote the development of forestry, which solved the inherent problems in forestry development while expanding the area of forestland and laid the policy foundation for sustainable development of forestry (Appendix A, Table A1).

In 2003, the Chinese government further promulgated the Decision on Accelerating the Development of Forestry, which provided concrete measures for forestry development by adjusting the structure of forestry industry and strengthening the construction of forestry bases (refer to the attachment for details). This series of policies and measures strongly promoted the development of forestry and the process of forestry modernization. The gross forestry product entered the medium-growth regime from Q2 2003 to Q3 2014.

However, China's gross forestry product was in the low-growth regime from Q4 2014 to Q1 2018. From the smoothed probability time dynamics trajectory shown in Figure 7, whether in the low-growth regime, medium-growth regime or rapid-growth regime, the 
smoothed probability of China's gross forestry product in different regimes were all close to the 1.00 level. This shows that the risk prevention and control of China's gross forestry product was more effective.

At the beginning of this century, the gross livestock product, which has a certain scale but is still immature in general, was basically in the low-growth regime due to the influence of the soft landing of China's economy (Figure 8). Several factors caused China's grow livestock product to drop from a rapid-growth to a low-growth regime. In 2004, the No. 1 Document encouraged the continuous improvement of feed, technology, equipment, and other inputs. In addition, there was increasing industry maturity in the processing of both dairy and meat products.

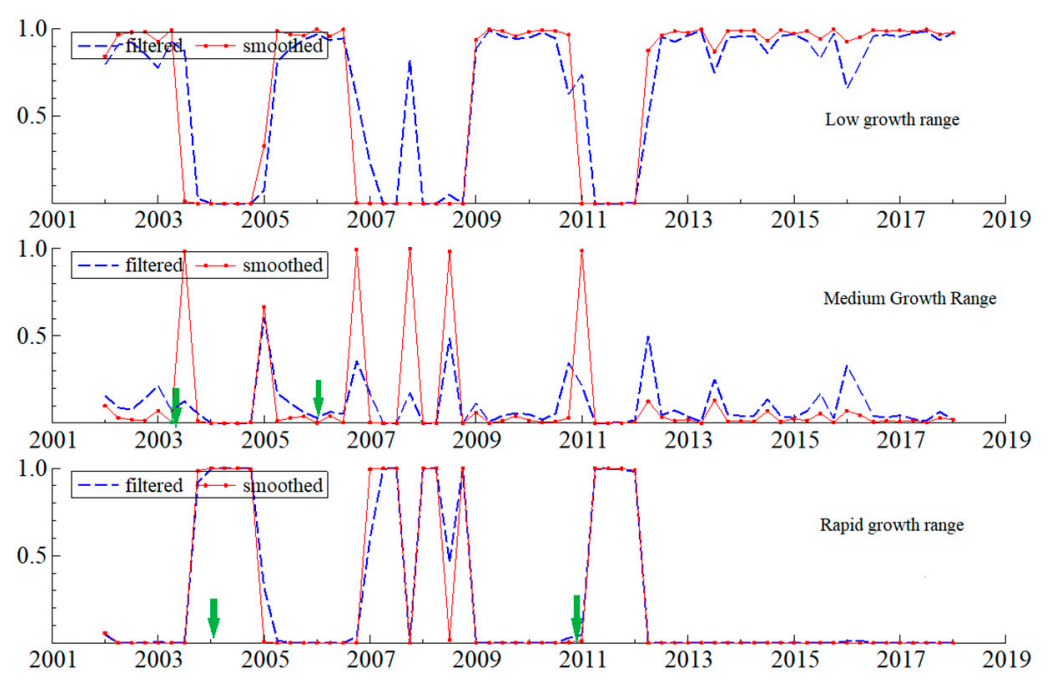

Figure 8. Filter probability and smoothing probability when the gross livestock product is in different growth regimes. Note: The green arrows mark the times when important policies were introduced.

In 2006, under the influence of the policy of abolishing agricultural tax and benefiting farmers, China's gross livestock product stepped into the rapid-growth regime again, fluctuating back and forth until falling back to a low-growth regime in 2009. In 2011, stimulated by the policy of accelerating the construction of water resources and infrastructure, it again entered the rapid-growth regime. From 2001 to 2012, there was an interaction between the rapid-growth regime and the low-growth regime, with a long-term low-growth regime after 2012. Unlike previous studies, our model sensitively captures the rapid-growth regime of China's livestock industry from (a) 2003-2005, (b) 2007-2008, (c) 2008-2009, and (d) 2010-2012, indicating that our model can more accurately simulate agricultural economic development.

China's fisheries industry was also affected by the soft landing of China's economy and was developing at a low rate in the early 2000s. However, fisheries entered a rapid-growth phase starting in 2004 under the influence of the first Document No. 1 (Figure 9). In 2008, the Chinese government introduced policies to strengthen the safety of fishery production, improve regulatory efforts, strengthen fishery production measures, and optimize departmental cooperation to ensure safe fishery production, while establishing a long-term mechanism to maintain sustainable fishery development (Appendix A, Table A1).

This series of comprehensive requirements as well as specific initiatives have greatly improved the pattern of fishery production, and under the new management mechanism, China's gross fishery production climbed to the medium-growth regime during the periods from Q3 2008 to Q1 2009 and from Q2 2010 to Q4 2012, while China's gross fishery production was in the rapid-growth regime during the periods from Q3 2008 to Q1 2009 and from Q2 2010 to Q4 2012. In general, China's fishery industry has been developing at a medium to high speed for a long time and has achieved a very good development trend. 
The possibility of China's fishery product moving into a low-growth regime still requires special attention.

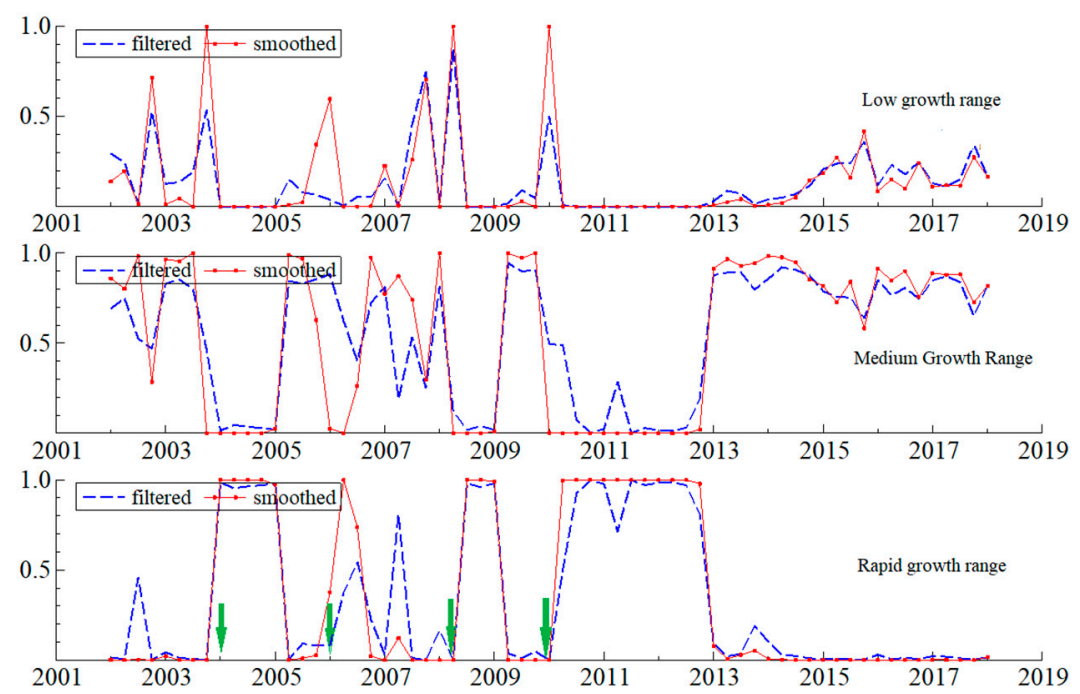

Figure 9. Filter probability and smoothing probability when the gross fishery product is in different growth regimes. Note: The green arrows mark the times when important policies were introduced.

Finally, we can see the basic overview of China's gross agricultural product in the lowgrowth regime, medium-growth regime, and rapid-growth regime. Specifically, China's agricultural economy was in the rapid-growth regime for 24 quarters in stages throughout the sample period (Figure 10). Looking back at history, during the period when China's gross agricultural product was in rapid growth, the Chinese government had major policies benefiting agriculture (Appendix A, Table A1).

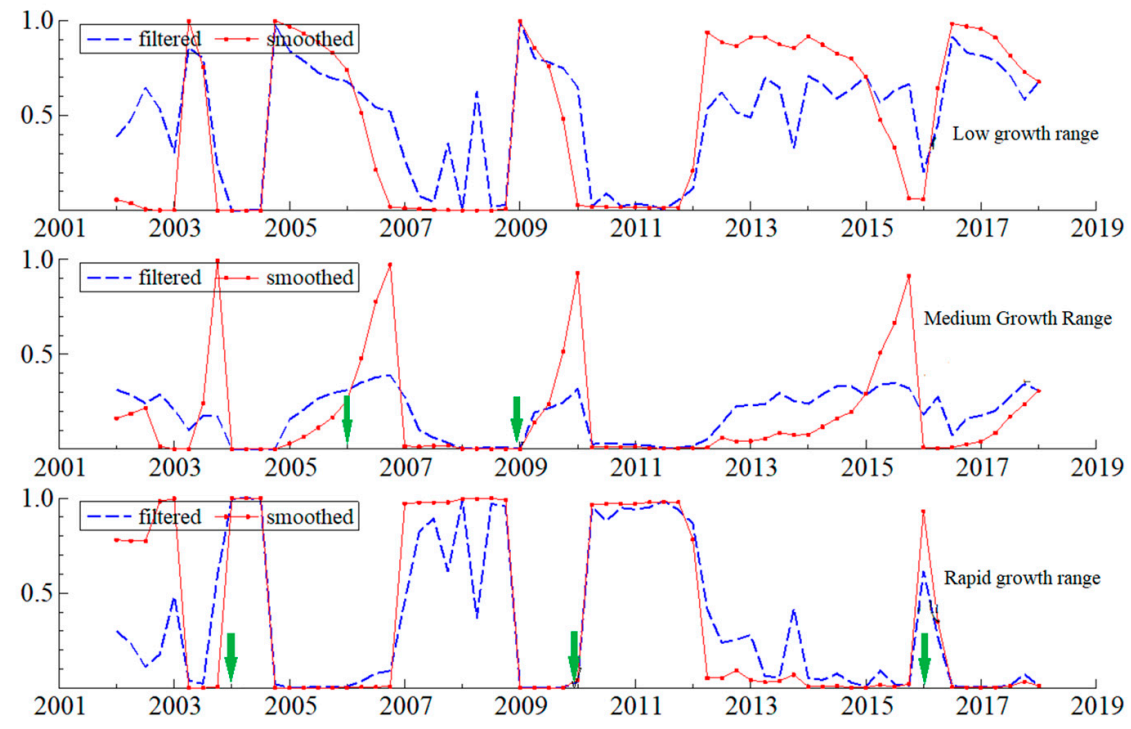

Figure 10. Filter probability and smoothing probability when the overall agricultural product is in different growth regimes. Note: The green arrows mark the times when important policies were introduced.

In 2004, the Chinese government issued the first No. 1 Document, which introduced direct subsidies for farmers, subsidies for good seeds and agricultural machinery, and subsidies for the purchase of agricultural machinery, and a minimum purchase price for rice, which greatly motivated farmers. In 2006, the agricultural tax regulations were abolished. The agricultural tax regulations, which had been implemented for nearly 50 years in New 
China, became historical records, and the system of taxing farmers by the area of land, which had lasted for 2600 years, was retired from the historical precedence.

The burden of farmers nationwide was reduced by CNY 133.5 billion per year, and the per capita burden was reduced by about CNY 140. After 2009, the Chinese government implemented the property rights policy of giving farmers fuller and more secure rights to contracted land management and indicated that the existing land contracting relationship would remain stable and unchanged for a long time. In 2010, the Chinese government made it clear that it was committed to giving full play to the role of efficient allocation of resources in promoting agricultural development, and to achieving increased efficiency in agricultural development by improving the allocation of resource factors. This injected confidence and vitality into the agricultural economy, and China's agricultural economy once again entered a high-speed growth regime. As the above-mentioned policy dividend receded, China's total agricultural output value shifts to a low-growth regime after a brief transition to a medium-growth regime.

Overall, China's gross agricultural product generally fluctuated frequently between the rapid-growth regime and the low-growth regime. The medium-growth regime occurred over shorter time periods. After 2012, except for 2016 when it was in the medium-highgrowth range for a short time, China's gross agricultural product was in the low-growth regime for a long time and was able to maintain relative stability (Tables 7 and 8).

The Chinese government has introduced beneficial agricultural policies every year since 2004. However, the growth of China's agricultural economy fluctuated between fast and low growth. After 2012, despite active fiscal policy, and, except for one quarter of fast growth in 2016, it has been in a low growth trend for a long time. This fully illustrates the vulnerability of agricultural economic growth and indicates that the government should pay attention to agricultural development in the long-term and increase policy support.

Comparing Figures 6-10 with Figures 1-5, we can see that the changes in the total output value of the agriculture, forestry, livestock, fishery, and overall agriculture industries show some similarities. Specifically, the time range of the "fast-growth regime" for each industry shown in Figures 5-8 corresponds to the period when the "fluctuation component" is relatively strong as shown in Figures 1-5, and the time range of the low-growth regime for each industry shown in Figures 6-10 corresponds to the period when the "fluctuation component" is relatively calm as shown in Figures 1-5. This implies that the risk of shocks is higher when the growth rate of the total output of each industry was relatively high in the agriculture, forestry, livestock, fishery, and overall agriculture industries and less uncertain when the growth rate of the total output of each industry was relatively low.

\section{Discussion}

\subsection{Contrast to Prior Studies}

Since China is still a developing country, the level of development of China's rural areas still lags behind that of the developed world, and agricultural production is still the main source of income for many Chinese farmers. Development remains a major issue for the Chinese government now and in the future. Therefore, in order to better understand the implications of our results, we need to compare and contrast our results to previous studies.

First, based on the above-mentioned empirical findings, we found that China's agricultural economy maintained a relatively good development with the support of the benefit agriculture policy during the sample period, i.e., the probability of maintaining China's agricultural economy in the fast-growth regime was $p_{33}=0.8020$ and had an average duration of 5.05 quarters, which is only slightly lower than the average duration of 6.65 quarters in the low-growth regime. This indicates that China's agricultural economy developed relatively well during periods following the agricultural support policies, which is consistent with prior studies [13-15].

Second, we found that the agricultural economy tended to maintain a low-growth rate, with the highest maintenance probability of $p_{11}=0.8425$ and the longest average duration of 6.35 quarters, which is consistent with the results of another study [34], demonstrating 
that China's agricultural economy is not easy to move into the expansion phase of its economic cycle. Our results are also consistent with research showing that maintaining rapid long-term growth in the agricultural economy is not easy due to factors such as excessive consumption of natural resources and environmental pollution [2].

A possible reason for this phenomenon is that the law of diminishing marginal returns is particularly evident in traditional agriculture due to natural conditions. Since the amount of resources invested in agriculture, such as land, is fixed, increasing the labor force will not increase the agricultural output significantly, resulting in slow agricultural growth. This pattern is particularly evident in developing countries where technological progress in agriculture is slow. Another possible reason is that since the demand for agricultural products typically lacks elasticity, an increase in the supply of agricultural products will cause the prices of agricultural products to fall, and hence an increase in production will not lead to an increase in income, which will, in turn, lead to a slow growth in agricultural output.

Third, based on the results of our empirical tests, we distinguished three growth statuses of China's agricultural economy-low, medium, and rapid-and we show their specific transfer paths in Figures 6-10. Specifically, China's agricultural economy was in the rapid-growth regime for 24 quarters in stages throughout the sample period. These rapid- growth states are clearly synchronized with the timing of important agricultural policies. Our analysis suggests that the possible reasons for the shifts to the rapid-growth regime are the introduction of major pro-agricultural policies by the Chinese government.

For example, in 2004, the Chinese government issued the first "Document No. 1" in the time period under examination, which introduced "direct subsidies for farmers, subsidies for good seeds and agricultural machinery purchases, and a minimum purchase price for rice," that greatly motivated farmers to produce more agricultural products. China's total agricultural output value also entered a high-growth zone. In 2006, when the agricultural tax regulations were abolished, China changed from an agricultural tax-raising country to an agricultural subsidy country, and the total agricultural output value entered a high-growth zone at the same time. In 2009, the Chinese government implemented the property rights policy of "granting farmers more complete and more secure rights to contracted land management and the existing land contract relationship should remain stable and unchanged for a long time."

From 2009 to 2010, a series of major initiatives for the benefit of farmers were proposed, including improving the policy system for the benefit of farmers, focusing on promoting the allocation of resources to rural areas, promoting the transformation of agricultural development, and improving the level of modern agricultural equipment. It also includes accelerating the improvement of rural people's livelihood, narrowing the gap between the development of urban and rural public utilities, coordinating the reform of urban and rural areas, and enhancing the vitality of agricultural and rural development. This was intended to enhance the vitality of agricultural and rural development, to promote urbanization actively and steadily, with the development of small and medium-sized cities and small towns as the focus, and to deepen the reform of the household registration system, etc. This has injected confidence, capital, technology, and vitality into China's agricultural economy, which has once again stepped into a high-speed growth regime. The above results support the findings of Qiao et al. [12], Jin and Deininger [13], Deininger et al. [14], and Xi et al. [32] that demonstrated agricultural growth is influenced by policies and institutions.

In addition, our research results show that China's agriculture, forestry, and animal husbandry tended to grow at a low rate. It was in the low-growth regime for a long time after 2011. The recent low-growth rate of the Chinese agricultural economy has been previously documented [34]. Policymakers should pay attention to this issue and continue to rely on agricultural support policies to avoid food shortages in China as well as adverse macroeconomic outcomes.

In this paper, the causal explanation of the correlation between agricultural economic cycles and government support policies is based on the common sense judgment of temporal synchronization and is not the result of empirical studies constructed using specialized 
models, such as Data Envelopment Analysis (DEA), Common Agricultural Policy Regionalized Impact (CAPRI), Propensity Score Matching (PSM), and other modeling methods. Hence, the generalizability of our results may be limited. Using specialized policy efficiency assessment models to evaluate the efficiency of agricultural support policies in China may be a fruitful, future research direction.

\subsection{Policy Recommendations}

Since China is still a developing country. The level of development of China's rural areas still lags behind that of the developed world, and agricultural production is still the main source of income for many Chinese farmers. Development remains a major issue for the Chinese government now and for the foreseeable future. Therefore, based on the results of our study, we propose the following policy recommendations.

First, there is a large body of theoretical and empirical research that shows a strong correlation between agricultural policy and agricultural development. China's current agricultural policies have achieved relatively good results. Therefore the current agricultural policy in the form of the annual Central Government Document No. 1 should be continued.

Secondly, agriculture, forestry, animal husbandry, and fisheries each have their own industry characteristics. Past research results show that the impacts of policies are rather limited with the exception of fisheries. Therefore, the formulation of agricultural policies in line with the development characteristics and stages of each industry may achieve better policy results.

Finally, China is a vast country with a wide range of regional development levels, and the geographical characteristics of agricultural development vary. Therefore policymakers should consider this situation and delegate policy-making authority to provincial governments or lower institutions. This is especially true for autonomous regions, autonomous prefectures, and even autonomous counties that are less developed. These institutions may be able to develop policies in their own regions that are more in line with the level of local agricultural development. Financial and policy supports from the central government could be channeled to allow for more local control if policy makers can be convinced that this improves productivity. Thus, it may be possible to promote the development of Chinese agriculture better than the current grand unified agricultural policy.

Because this study is not an assessment of the effectiveness of current agricultural policies in China, the above policy recommendations may be somewhat biased. Our next research aims to specifically assess the policy efficiency of China's current agricultural policies. Therefore it may be possible to make more nuanced policy recommendations that are more in line with China's agricultural development after completing this additional research.

\section{Conclusions}

Based on the above findings and discussion, it can be concluded that China's agricultural economy has achieved relatively good development in the context of the country's rapid macroeconomic development and agricultural policies, especially the fishery industry, which has been able to maintain medium to high-growth rates. However, in the long-term, China's agricultural economy tends to maintain a low-growth rate. Since 2011, China's agriculture, forestry, and livestock industries have mostly maintained low-growth rates. In order to maintain agricultural development in China, the Chinese government should continue its current agricultural support policies, especially increasing support for the agriculture, forestry, and livestock industries. Future research should focus on using specialized policy assessment models to evaluate the efficiency of agricultural support policies in China.

Author Contributions: Conceptualization, X.G., J.S., R.Z., and C.W.; methodology, X.G., J.S., and P.L.; formal analysis, X.G., J.S., and C.W.; writing - original draft preparation, X.G. and J.S.; writingreviewing and editing, X.G., P.L., and R.Z.; supervision, P.L. and C.W. All authors have read and agreed to the published version of the manuscript.

Funding: This research received no external funding. 
Institutional Review Board Statement: Not applicable for studies not involving humans or animals.

Informed Consent Statement: Not applicable for studies not involving humans.

Data Availability Statement: The data presented in this study are available in article.

Acknowledgments: We gratefully acknowledge Yu Zhu for his comments and suggestions for improvement, and Yudong Chen for checking the paper. Similarly, we also thank Qiusheng Zhang, Li Li, Changsheng Gao, Zisheng Fang, Xinsheng Deng, Qing Chang, Dehong Liu, and Zizheng Wu for their advice and help with the paper. Finally, we are particularly grateful to Aaron K. Hoshide for his editorial comments and to the two anonymous reviewers for their review comments.

Conflicts of Interest: The authors declare no conflict of interest.

\section{Appendix A}

Table A1. Summary of the Chinese government's main agricultural support policies from 2002-2018.

\begin{tabular}{|c|c|}
\hline Year & Summary of Major Agricultural Policies \\
\hline 2002 & $\begin{array}{l}\text { Regulations on Restoring Farmland to Forest } \\
\text { Returning farmland to forest is to protect and improve the ecological environment in the } \\
\text { west, the sloping arable land that is prone to soil erosion and the arable land that is prone } \\
\text { to land sanding, stop cultivation in a planned and step-by-step manner. In line with the } \\
\text { principle that it is appropriate to plant trees, irrigation, grass, and the combination of trees, } \\
\text { irrigation, and grass, planting forests and grasses according to local conditions to restore } \\
\text { forest and grass vegetation. The state implements the system of funds and food subsidies } \\
\text { for returning farmland to forest, the state provides appropriate subsidized food, seedling } \\
\text { planting fees, and cash (living expenses) subsidies to those returning farmland to forest for } \\
\text { a certain period of time without compensation according to the approved area of returning } \\
\text { farmland to forest. The Yellow River Basin and the northern region, each mu of fallow land } \\
\text { is subsidized with } 100 \text { kg of raw food and CNY } 20 \text { of cash per year, and at least } 8 \text { years for } \\
\text { ecological forest, } 5 \text { years for economic forest, and } 2 \text { years for grass. Each mu of fallow land } \\
\text { and forest able wasteland subsidies has a seedling reforestation fee of CNY } 50 \text {. }\end{array}$ \\
\hline
\end{tabular}

The decision of the State Council of the Communist Party of China (CPC) Central Committee on Accelerating the Development of Forestry

Stabilize the land contract relationship and allow the reasonable transfer of land use rights under the principle of law, voluntarily and with compensation. Development of private fast-growing forests and its related industries, the implementation of agroforestry compound management, turning potential resource advantages into realistic economic

2003 advantages, to achieve the effect of increasing farmers' income, agricultural efficiency and environmental improvement. Encourage pulp and paper enterprises to cross-region, cross-sector, cross-ownership to establish a paper forest base. In the forestry policy, the first should be clear property rights, with the responsibility to the household. In accordance with the principle of "who makes who has, who operates who gains," further extend the use of forest land, allowing inheritance, transfer, mortgage, lease, and access to the secondary market flow. Second, to relax logging restrictions and revitalize forest assets.

Opinions of the State Council of the Central Committee of the Communist Party of China on Several Policies to Promote Increased Incomes of Farmer

On 31 December 2003, the "Opinions of the State Council of the Central Committee of the Communist Party of China on Several Policies to Promote Increased Incomes for Farmers" was issued and published on 9 February 2004. A prominent problem of agricultural and rural development at that time was the difficulty of increasing farmers' income. The income gap between urban and rural residents widened from 1.8:1 in the 1980s to 3.1:1, and the difficulty of increasing farmers' income not only restricted the development of the rural economy but also affected the growth of the national economy as a whole. The "Opinions" proposed to "adhere to the 'more to give, less to take, let live' policy, adjust the agricultural structure, expand employment of farmers, accelerate scientific and technological progress, deepen rural reform, increase agricultural investment, strengthen support for agricultural protection, and strive to achieve a relatively rapid growth in farmers' income, as soon as possible to reverse the income gap between urban and rural residents The trend of widening income gap between urban and rural residents." The document contains 22 articles, putting forward a series of high gold content, pointing to clear and practical policy measures. 
Table A1. Cont.

\begin{tabular}{|c|c|}
\hline Year & Summary of Major Agricultural Policies \\
\hline 2005 & $\begin{array}{l}\text { Opinions of the State Council of the Central Committee of the Communist Party of China } \\
\text { on Several Policies to Further Strengthen Rural Work and Improve Comprehensive } \\
\text { Agricultural Production Capacity } \\
\text { In February 2005, the "Opinions of the State Council of the Central Committee of the } \\
\text { Communist Party of China on a number of policies to further strengthen rural work to } \\
\text { improve the comprehensive production capacity of agriculture" was issued. The } \\
\text { document pointed out the current and future period, to strengthen the construction of } \\
\text { agricultural infrastructure, accelerate the progress of agricultural science and technology, } \\
\text { improve the comprehensive production capacity of agriculture, as a major and urgent } \\
\text { strategic task, and effectively grasp it. Additionally, stressed that we should "strictly } \\
\text { protect the arable land as the basis, to strengthen the construction of agricultural water } \\
\text { conservancy as the focus, to promote scientific and technological progress as a support, to } \\
\text { improve the service system as a guarantee, and strive to make efforts in the next few } \\
\text { years, so that the material and technical conditions of agriculture significantly improved, } \\
\text { land product rate and labor productivity significantly increased, the overall efficiency and } \\
\text { competitiveness of agriculture significantly enhanced." }\end{array}$ \\
\hline
\end{tabular}

Several Opinions of the State Council of the CPC Central Committee on Promoting the Construction of a New Socialist Countryside

On 21 February 2006, the "Opinions of the State Council of the Central Committee of the Communist Party of China on Promoting the Construction of a New Socialist Countryside" was released. The document points out that building a new socialist countryside is a major historical task in China's modernization process. Only by developing the rural economy, building a good home for farmers, and enabling them to lead a prosperous life can we ensure that all people share the fruits of economic and social development and continuously expand domestic demand and promote sustainable development of the national economy. The full text of the document contains 32 articles, eight parts. The document emphasizes the need to adhere to the development of the rural economy as the center, to further liberate and develop the rural productive forces. Adhere to the "more to less to take the live" approach, focusing on the "more to" efforts to mobilize a wide range of forces to participate.

Decision of the Standing Committee of the National People's Congress on the Abolition of the Regulations of the People's Republic of China on Agricultural Tax

On 29 December 2005, the 19th meeting of the Standing Committee of the 10th National People's Congress decided to repeal the Regulations of the People's Republic of China on Agricultural Tax from 1 January 2006. As a result, the state no longer levies a separate tax on agriculture.

Several Opinions of the State Council of CPC Central Committee on Actively Developing Modern Agriculture and Solidly Promoting the Construction of a New Socialist Countryside On 29 January 2007, the "CPC Central Committee and State Council on the active development of modern agriculture to solidly promote the construction of a new socialist countryside of a number of opinions" was published. The document clearly pointed out that the construction of a new socialist countryside should put the construction of modern agriculture in the first place. The construction of the new socialist countryside has received an enthusiastic response from the grassroots. However, there are some deviations in practice. Emphasis on the new rural construction should put the development of modern agriculture in the first place, which is conducive to the serious implementation of the spirit of the Fifth Plenary Session of the Sixteenth Central Committee around the world, the new socialist countryside construction to move forward solidly and healthily. The document proposes to equip agriculture with modern material conditions, transform agriculture with modern science and technology, upgrade agriculture with modern industrial systems, promote agriculture with modern forms of operation, lead agriculture with modern development concepts, develop agriculture with training new farmers, improve the level of agricultural water conservancy, mechanization and information technology, improve land product rate, resource utilization and agricultural labor productivity, improve agricultural quality, efficiency and competitiveness. 
Table A1. Cont.

\begin{tabular}{|c|c|}
\hline Year & Summary of Major Agricultural Policies \\
\hline & $\begin{array}{l}\text { Several Opinions of the CPC Central Committee and State Council on Effectively } \\
\text { Strengthening Agricultural Infrastructure Construction to Further Promote Agricultural } \\
\text { Development and Increase Farmers' Income } \\
\text { On } 30 \text { January 2008, the "Opinions of the Central Committee of the Communist Party of } \\
\text { China and the State Council on Effectively Strengthening Agricultural Infrastructure to } \\
\text { Further Promote Agricultural Development and Increase Farmers' Income" was announced. } \\
\text { That year's Central Document No. } 1 \text { deepened the requirements of last year's Central } \\
\text { Document No. } 1 \text { on developing modern agriculture as the primary task of new rural } \\
\text { construction, grasping the key link between maintaining economic stability and promoting } \\
\text { agricultural development, and also taking into account the work of all aspects of rural areas. } \\
\text { There are more than } 40 \text { policy requirements and measures in the whole document, among } \\
\text { which the agriculture and farmers can be directly benefited as "three obvious," "three } \\
\text { adjustments," "four increases," "four improvements," "four increase," and "two } \\
\text { substantial." Embodies the benefits to farmers to gradually increase, with the growth of } \\
\text { national financial resources to the "three rural" support to further increase the requirements. }\end{array}$ \\
\hline
\end{tabular}

General Office of the State Council on strengthening the work of fishery production safety notice Comprehensively implement the production safety responsibility system for fisheries,

2008 further strengthen safety management and supervision, increase investment, improve infrastructure, improve technical equipment, improve laws and regulations, and constantly improve the safety quality of practitioners and disaster prevention and avoidance capabilities, and strive to build a long-term mechanism for fisheries production safety, effectively curb fishing safety accidents, effectively protect the lives and property of the people, and promote the safe development of the fisheries economy. Expansion of a number of new safety from the wind, supporting the perfect fishing port, so that the national coastline within an average of $200 \mathrm{~km}$ above the first-class fishing port is able to provide services for $45 \%$ of the marine fishing vessels. Key fishing ports were equipped with safety monitoring equipment, the construction of marine fisheries ship management dynamic monitoring system, fishing vessel safety equipment testing, and inspection base and fisheries crew training base, so that serious fishing vessel accidents are significantly control. By 2015, the formation of a more complete fishery production safety support and security system, fisheries safety supervision and disaster prevention and mitigation capabilities are significantly enhanced, the quality of practitioners have improved to a certain extent, the fisheries safety production situation has improved significantly. Specific measures include: Strengthening the construction of fishing port safety infrastructure, vigorously improve the quality of fishing vessel safety, and actively promote the construction of fisheries safety communication network, and strive to improve fisheries safety technology and equipment. Increase financial investment, improve the production of fishery safety laws and regulations and systems, promote scientific and technological advances in fisheries safety, improve fisheries safety risk protection mechanism, etc.

Several Opinions of the CPC Central Committee and State Council on Promoting Stable Development of Agriculture and Sustained Incomes of Farmers in 2009

The 2009 No. 1 Document "the CPC Central Committee and the State Council on 2009 to promote the stable development of agriculture and farmers continue to increase income of a number of opinions" presents four new highlights. First, the support for farmers to grow food has been increased again. Including increased investment in agricultural infrastructure and scientific and technological services, and increased direct subsidies to agriculture. Second, to increase efforts to solve the problem of employment of migrant workers. The document proposes urban and rural infrastructure construction and new

2009 public welfare jobs, as much as possible to use more migrant workers. To take work for food and other ways to guide farmers to participate in agricultural and rural infrastructure construction. Third, the rural livelihood construction focus on the rural power grid construction, rural road construction, rural drinking water safety project construction, rural biogas construction, rural housing renovation, and other five areas. Fourth, the transfer of agricultural land emphasizes further regulation. For adhering to the basic rural management system, the 2009 No. 1 Document first emphasized the implementation and protection of farmers' land rights and interests, focusing on two aspects of work: The ownership of collectively owned land is further defined clearly and its rights and interests are protected. The contracted land plots are identified, registered, and certified. 
Table A1. Cont.

\begin{tabular}{|c|c|}
\hline Year & Summary of Major Agricultural Policies \\
\hline 2010 & $\begin{array}{l}\text { Several Opinions of the State Council of the CPC Central Committee on Increasing the } \\
\text { Efforts to Coordinate Urban and Rural Development to Further Strengthen the } \\
\text { Foundation of Agricultural and Rural Development } \\
\text { In early 2010, the "Opinions of the State Council of the Central Committee of the Communist } \\
\text { Party of China on Increasing the Efforts to Integrate Urban and Rural Development to Further } \\
\text { Strengthen the Foundations of Agricultural and Rural Development" was released, further } \\
\text { improving and strengthening good policies for the "three rural areas" on the basis of maintaining } \\
\text { policy continuity and stability, and putting forward a series of new major principles and } \\
\text { measures, including improve the policy system for a strong agricultural policy system, promote } \\
\text { the allocation of resources to rural areas, improve the level of modern agricultural equipment, } \\
\text { promote the transformation of agricultural development, accelerate the improvement of rural } \\
\text { people's livelihood, narrow the gap between urban and rural public utilities development, } \\
\text { coordinate urban and rural reform, enhance the vitality of agricultural and rural development. } \\
\text { Strengthen the construction of rural grass-roots organizations, and consolidate the Party's ruling } \\
\text { base in rural areas. The document places special emphasis on institutional innovation to } \\
\text { promote the development of urbanization. Propose to actively and steadily promote } \\
\text { urbanization, improve the level of urban planning and development quality, to strengthen the } \\
\text { development of small and medium-sized cities and small towns as the focus. Deepen the reform } \\
\text { of the household registration system, accelerate the implementation of policies to relax the } \\
\text { conditions for settling in small and medium-sized cities and small towns, especially in counties } \\
\text { and central towns, and promote the eligible agricultural transfer population to settle in cities and } \\
\text { towns and enjoy the same rights and interests as local urban residents. }\end{array}$ \\
\hline
\end{tabular}

The CPC Central Committee and State Council Decision on Accelerating the Reform and Development of Water Resources

On 29 January 2011, the "CPC Central Committee and the State Council on the decision to accelerate the reform and development of water conservancy" was released, the theme of accelerating the reform and development of water conservancy. This is the first time in

201162 years since the founding of new China, the central document on the work of water resources for comprehensive deployment. The document proposes to put the work of water resources on a more prominent position, focusing on accelerating the construction of agricultural water conservancy, to promote the leapfrog development of water resources. Proposes to strive for 5 to 10 years of efforts to fundamentally reverse the situation of the obvious lag in water conservancy construction.

The CPC Central Committee and State Council on Accelerating Agricultural Science and Technology Innovation to Continuously Enhance the Ability to Ensure the Supply of Agricultural Products

The "Opinions of the State Council of the CPC Central Committee on Accelerating Agricultural Science and Technology Innovation to Continuously Enhance the Supply Assurance Capability of Agricultural Products," released in February 2012, highlights the deployment of agricultural

2012 science and technology innovation and makes the promotion of agricultural science and technology innovation the focus of the work of the "three rural areas." Two of the most popular policies: One is the public, basic, social discourse on agricultural science and technology. The other is the township agricultural personnel salaries and wages to be linked to the average income of local institutions. The grassroots agricultural extension system reform and construction demonstration county project basically covers all agricultural counties, agricultural technology extension institutions conditions, and construction projects cover all townships.

Several Opinions of the CPC Central Committee and State Council on Accelerating the Development of Modern Agriculture and Further Enhancing the Vitality of Rural Development On 31 January 2013, the "Opinions of the State Council of the Central Committee of the Communist Party of China on Accelerating the Development of Modern Agriculture and Further Enhancing the Vitality of Rural Development" was released. The document makes comprehensive arrangements for "accelerating the development of modern agriculture and further enhancing the vitality of rural development," requiring that we must respond to the changes in the stage, follow the laws of development, enhance the sense of worry, and make national efforts to persistently strengthen agriculture, benefit the countryside, and enrich farmers. In accordance with the work objectives of ensuring supply and income, reform and innovation to add vitality, increase the efforts of rural reform, policy support, science and technology-driven efforts. 
Table A1. Cont.

\begin{tabular}{|c|c|}
\hline Year & Summary of Major Agricultural Policies \\
\hline 2014 & $\begin{array}{l}\text { Several Opinions of the CPC Central Committee and State Council on Comprehensively } \\
\text { Deepening Rural Reform and Accelerating Agricultural Modernization } \\
\text { In January 2014, the "Opinions of the State Council of the Central Committee of the } \\
\text { Communist Party of China on Comprehensively Deepening Rural Reform and } \\
\text { Accelerating Agricultural Modernization" was released. It is pointed out that to } \\
\text { comprehensively deepen rural reform, we should adhere to the direction of socialist } \\
\text { market economy reform, handle the relationship between the government and the market, } \\
\text { and stimulate rural economic and social vitality. Encourage exploration and innovation, } \\
\text { and promote land transfer in an orderly manner under the premise of protecting the } \\
\text { interests of farmers. Tailor the reform to local conditions, proceed in a gradual and } \\
\text { orderly manner, and do not engage in a "one-size-fits-all" approach or pursue a one-step } \\
\text { solution. Allow the adoption of different, transitional systems and policy arrangements. } \\
\text { To integrate urban and rural linkages, give farmers more property rights, promote equal } \\
\text { exchange of urban and rural factors and balanced allocation of public resources, so that } \\
\text { farmers can participate equally in the modernization process and share the fruits } \\
\text { of modernization. }\end{array}$ \\
\hline
\end{tabular}

Several Opinions of the CPC Central Committee and State Council on Increasing Reform and Innovation to Accelerate the Construction of Agricultural Modernization The 2015 Central Document No. 1, "Opinions of the State Council of the Central Committee of the Communist Party of China on Increasing Reform and Innovation to Accelerate the Construction of Agricultural Modernization," points out that we should actively adapt to the new normal of economic development, follow the general requirements of stabilizing food and increasing income, improving quality and efficiency, and driving innovation, continue to comprehensively deepen rural reform,

2015 comprehensively promote the construction of the rule of law in rural areas, and promote the simultaneous development of new industrialization, information technology, urbanization and agricultural modernization. Efforts to improve food production capacity to explore new potential, in the optimization of agricultural structure to open up new ways, in the transformation of agricultural development to seek new breakthroughs, in the promotion of farmers to obtain new results on income, in the construction of a new countryside to take new steps to provide strong support for sustainable and healthy economic and social development.

Several Opinions of the State Council of the Central Committee of the Communist Party of China on Implementing the New Concept of Development and Accelerating Agricultural Modernization to Achieve the Goal of Comprehensive Well-off In January 2016, the "Opinions of the State Council of the Central Committee of the Communist Party of China on Implementing the New Concept of Development and Accelerating Agricultural Modernization to Achieve the Goal of Overall Well-off" was released. All regimes and departments are required to firmly establish and thoroughly

2016 implement the development concept of innovation, coordination, green, openness and sharing, vigorously promote agricultural modernization, and ensure that hundreds of millions of farmers will join the people of the country to move into an overall well-off society. The document proposes to use the new concept of development to crack the "three rural" new problems, thicken the advantages of agricultural and rural development, increase innovation-driven efforts to promote the supply-side structural reform of agriculture, accelerate the transformation of agricultural development, to maintain stable development of agriculture, and farmers continue to increase income. 
Table A1. Cont.

\begin{tabular}{|c|c|}
\hline Year & Summary of Major Agricultural Policies \\
\hline 2017 & $\begin{array}{l}\text { Several Opinions of the State Council of the Central Committee of the Communist Party } \\
\text { of China on Deepening the Structural Reform on the Supply Side of Agriculture and } \\
\text { Accelerating the Cultivation of New Dynamic Energy for Agricultural and } \\
\text { Rural Development } \\
\text { In February 2017, the "CPC Central Committee and State Council on deepening the } \\
\text { supply-side structural reform of agriculture to accelerate the cultivation of new dynamics } \\
\text { of agricultural and rural development of a number of opinions" was released. The } \\
\text { document clearly points out that the main line of work for the current and future period } \\
\text { of the "three rural areas" should be to deeply promote the structural reform of the } \\
\text { agricultural supply side. After years of efforts, China's agricultural and rural } \\
\text { development has entered a new historical stage. The main contradiction in agriculture } \\
\text { from the total lack of structural contradictions, highlighted by the stage of oversupply and } \\
\text { undersupply coexist, the main aspect of the contradiction in the supply side. Urgent } \\
\text { requirements to further promote the supply-side structural reform of agriculture, } \\
\text { accelerate the cultivation of new dynamics of agricultural and rural development. The } \\
\text { document points out that to promote the supply-side structural reform of agriculture, } \\
\text { based on ensuring national food security, closely around the changes in market demand, } \\
\text { to increase farmers' income, to ensure effective supply as the main goal, to improve the } \\
\text { quality of agricultural supply as the main direction, to institutional reform and } \\
\text { institutional innovation as the fundamental way. Additionally, stressed that the } \\
\text { supply-side structural reform of agriculture is a long-term process, we must face the } \\
\text { difficulties and challenges, try to reduce the cost of reform, and actively prevent the risk } \\
\text { of reform. At the same time, the further implementation of the rural land three rights of } \\
\text { separation, to encourage the appropriate scale of land transfer. }\end{array}$ \\
\hline 2018 & $\begin{array}{l}\text { Opinions of the State Council of the Central Committee of CPC on Implementing the } \\
\text { Strategy of Rural Revitalization } \\
\text { On } 2 \text { January 2018, the "Opinions of the State Council of the Central Committee of the } \\
\text { Communist Party of China on the Implementation of the Rural Revitalization Strategy" } \\
\text { was released. Around the implementation of the rural revitalization strategy, the } \\
\text { document plans a series of major initiatives and is the top-level design for the } \\
\text { implementation of the rural revitalization strategy. The document has two important } \\
\text { features: First, it is comprehensive in management. It makes comprehensive } \\
\text { arrangements for the overall promotion of rural economy, politics, culture, society, } \\
\text { ecological civilization, and the construction of the Party. The second is to manage the } \\
\text { long-term. In accordance with the strategic arrangement proposed by the 19th Party } \\
\text { Congress of building a moderately prosperous society and achieving the second century } \\
\text { goal in two stages, the document deploys the three stages of implementing the rural } \\
\text { revitalization strategy according to the principle of "far and coarse, near and fine." }\end{array}$ \\
\hline
\end{tabular}

\section{References}

1. Burns, A.F.; Wesley, C.M. Measuring Business Cycles; National Bureau of Economic Research: Cambridge, MA, USA, 1946; pp. 384-417.

2. Fan, S. Public Expenditures, Growth, and Poverty: Lessons from Developing Countries. Asean Econ. Bull. 2009, 26, 235. [CrossRef]

3. Pan, D.; Ying, R. Research on the relationship between water resources and agricultural economic growth in China-Based on panel VAR model. China Popul. Resour. Environ. 2012, 22, 161-166.

4. Wu, Q.; Zhou, X.; Feng, Z. The impact of infrastructure on agricultural economic growth-A study based on inter-provincial panel data of China from 1995-2010. China Econ. Issues 2015, 3, $29-37$.

5. Ofana, O.G.; Effiong, C.E.; Eko, E.O. Constraints to agricultural development in Nigeria. Int. J. Dev. Econ. Sustain. 2016, 4, 19-33.

6. Sylwester, K. R\&D and economic growth. Knowl. Soc. 2001, 13, 71-84. [CrossRef]

7. Andersen, M.A. Public investment in U.S. agricultural R\&D and the economic benefits. Food Policy 2015, 51, 38-43. [CrossRef]

8. Wang, J. Research on the Interactive Relationship between China's Agricultural Research Investment and Agricultural Eco-nomic Growth. Agric. Technol. Econ. 2009, 1, 103-109.

9. Yang, C.; Zhang, J.; Zhao, K. Demonstration on the relationship between agricultural science and technology resources and agricultural economic development. China Popul. Resour. Environ. 2011, 21, 113-118.

10. Kirchner, M.; Schmidt, J.; Kindermann, G.; Kulmer, V.; Mitter, H.; Prettenthaler, F.; Rüdisser, J.; Schauppenlehner, T.; Schönhart, M.; Strauss, F.; et al. Ecosystem services and economic development in Austrian agricultural landscapes-The impact of policy and climate change scenarios on trade-offs and synergies. Ecol. Econ. 2015, 109, 161-174. [CrossRef] 
11. Abdul-Rahim, A.S.; Sun, C.; Noraida, A.W. The Impact of Soil and Water Conservation on Agricultural Economic Growth and Rural Poverty Reduction in China. Sustainability 2018, 10, 4444. [CrossRef]

12. Qiao, Z.; Jiao, F.; Li, N. Changes in China's Rural Economic System and Agricultural Growth: An Empirical Analysis of China's Agricultural Growth from 1978 to 2004. Econ. Res. 2006, 7, 73-82.

13. Jin, S.; Klaus, D. Land rental markets in the process of rural structural transformation: Productivity and equity impacts from China. J. Comp. Econ. 2009, 37, 629-646. [CrossRef]

14. Deininger, K.; Jin, S.; Xia, F.; Huang, J. Moving off the farm: Land institutions to facilitate structural transformation and agricultural productiv-ity growth in China. World Dev. 2014, 59, 505-520. [CrossRef]

15. Lerman, Z. Land reform, farm structure, and agricultural performance in CIS countries. China Econ. Rev. 2009, 20, 316-326. [CrossRef]

16. Guth, M.; Smędzik-Ambroży, K.; Czyżewski, B.; Stępień, S. The Economic Sustainability of Farms under Common Agricultural Policy in the European Union Countries. Agriculture 2020, 10, 34. [CrossRef]

17. Susilastuti, D. Poverty Reduction Models: Indonesian Agricultural Economic Approach. Eur. Res. Stud. J. 2017, 20, 164-176. [CrossRef]

18. Boonyanam, N. Agricultural economic zones in Thailand. Land Use Policy 2020, 99, 102774. [CrossRef]

19. Chaudhary, D. Agricultural Policies and Rural Development in Nepal: An Overview. Res. Nepal J. Dev. Stud. 2018, 1, 34-46. [CrossRef]

20. Chanie, A.M.; Pei, K.Y.; Lei, Z.; Zhong, C.B. Rural Development Policy: What does Ethiopia Need to Ascertain from China Rural Development Policy to Eradicate Rural Poverty? Am. J. Rural. Dev. 2018, 6, 79-93. [CrossRef]

21. Corral, S.; Díaz, A.S.; Monagas, M.D.C.; García, E.C. Agricultural Policies and Their Impact on Poverty Reduction in Developing Countries: Lessons Learned from Three Water Basins in Cape Verde. Sustainability 2017, 9, 1841. [CrossRef]

22. Pernechele, V.; Jean, B.; Léopold, G. Agricultural policy incentives in sub-Saharan Africa in the last decade (2005-2016). Monit. Anal. Food Agric. Policies (MAFAP) Synth. Study 2018, 2143-2019-4790. [CrossRef]

23. Grabowski, R. Agricultural distortions and structural change. J. Asian Econ. 2013, 24, 17-25. [CrossRef]

24. Akbar, M.; Jamil, F. Monetary and fiscal policies' effect on agricultural growth: GMM estimation and simulation analysis. Econ. Model. 2012, 29, 1909-1920. [CrossRef]

25. Fang, H. The impact of monetary supply shocks on the agricultural economy under the conditions of an open economy-Based on the causal graph method. China Rural Econ. 2011, 8, 41-53.

26. Chen, D. Monetary policy, inflationary pressure and agricultural product prices. China Soft Sci. 2014, 7, 185-192.

27. Sánchez-Picón, A.; Aznar-Sánchez, J.A.; García-Latorre, J. Economic cycles and environmental crisis in arid southeastern Spain. A historical perspective. J. Arid Environ. 2011, 75, 1360-1367. [CrossRef]

28. Palma, I.P.; Toral, J.N.; Vázquez, M.R.P.; Fuentes, N.F.; Hernández, F.G. Historical changes in the process of agricultural development in Cuba. J. Clean. Prod. 2015, 96, 77-84. [CrossRef]

29. Chatterton, J.; Graves, A.; Audsley, E.; Morris, J.; Williams, A. Using systems-based life cycle assessment to investigate the environmental and economic impacts and benefits of the livestock sector in the UK. J. Clean. Prod. 2015, 86, 1-8. [CrossRef]

30. Ge, Y.; Zhao, R.; Liu, D. Causal factors of cyclical fluctuations in China's agricultural economy and their transmission mechanisms. Agric. Technol. Econ. 1998, 1, 46-49.

31. Guo, W. A study of agricultural volatility in China. Rural Econ. Soc. 1991, 2, 1-9.

32. Xi, L.; Peng, K. Analysis of China's rural economic system changes and agricultural cyclical growth. China Popul. Resour. Environ. 2010, 20, 123-129.

33. Sun, X. Analysis of the characteristics of my country's agricultural cycle fluctuations. Learn. Explor. 2011, 2, 168-169.

34. Sui, J.; Cai, Q. Identification of the path evolution of China's agricultural business cycle: Practice and experience since the reform and opening up. China Rural Econ. 2016, 9, 30-43.

35. Cheng, S.; López, M.A. Synergy analysis of agricultural economic cycle fluctuation based on ant colony algorithm. Open Phys. 2018, 16, 978-988. [CrossRef]

36. Yu, J.; Wu, J. The Sustainability of Agricultural Development in China: The Agriculture-Environment Nexus. Sustainability 2018, 10, 1776. [CrossRef]

37. Hejazi, M.; Marchant, M.A. China's evolving agricultural support policies. Choices 2017, 32, 1-7.

38. Huang, J.; Guolei, Y. Understanding recent challenges and new food policy in China. Glob. Food Secur. 2017, 12, 119-126. [CrossRef]

39. Huang, P.C.C. Is the family farm the approach for agricultural development in China? Open Times 2014, 2, 176-194.

40. Yao, Y.; Chen, W.; Li, X. Research on the relationship between environmentally friendly agricultural technology innovation and agricultural economic growth. China Popul. Resour. Environ. 2014, 24, 122-130.

41. Wang, L. Impact of ecological land use change on agricultural economy in the farming pastoral ecotone of northern China. China Rural Econ. 2009, 4, 80-85.

42. Skalin, J.; Teräsvirta, T. Another look at Swedish business cycles, 1861-1988. J. Appl. Econ. 1999, 14, 359-378. [CrossRef]

43. Hamilton, J.D. Analysis of time series subject to changes in regime. J. Econ. 1990, 45, 39-70. [CrossRef]

44. Leamer, E.; Potter, S. A Nonlinear Model of the Business Cycle; Federal Reserve Bank of New York: New York, NY, USA, 2003.

45. Moolman, E. A Markov switching regime model of the South African business cycle. Econ. Model. 2004, 21, 631-646. [CrossRef] 
46. de Medeiros, O.R.; Sobral, Y.D. A Markov Switching Regime Model of the Brazilian Business Cycle. SSRN Electron. J. 2007. [CrossRef]

47. Dicle, O. Sectoral Business Cycle Asymmetries and Regime Shifts: Evidence from Turkey. Appl. Econ. J. 2019, 26, 59-80.

48. Liu, J.; Sui, J.; Yan, C. My country's economic cycle wave dynamics and economic policy orientation under the financial crisis. China Ind. Econ. 2009, 8, 37-46.

49. Chen, L.; Liu, H. Research on the Asymmetry and Persistence of my country's Business Cycle Fluctuations. Econ. Res. 2007, 4, $43-52$.

50. Liu, J.; Sui, J. A Test of the Relationship between the Uncertainty of China's Currency Growth and Economic Growth (1980-2008). Chin. Soc. Sci. 2010, 4, 74-86, 221-222.

51. Sui, J.; Song, D. Analysis of the changes in the dynamic path of China's agricultural economic growth. Learn. Explor. 2014, 6, 106-109.

52. Krolzig, H.-M. Markov-Switching Vector Auto Regressions: Modelling, Statistical Inference, and Application to Business Cycle Analysis; Springer Science \& Business Media: Berlin, Germany, 2013; Volume 454.

53. Hodrick, R.J.; Prescott, E.C. Postwar U.S. Business Cycles: An Empirical Investigation. J. Money Crédit Bank. 1997, $29,1-16$. [CrossRef] 